\title{
Hybrid and Composite Scaffolds Based on Extracellular Matrices for Cartilage Tissue Engineering
}

Citation for published version (APA):

Setayeshmehr, M., Esfandiari, E., Rafieinia, M., Hashemibeni, B., Taheri-Kafrani, A.,

Samadikuchaksaraei, A., Kaplan, D. L., Moroni, L., \& Joghataei, M. T. (2019). Hybrid and Composite Scaffolds Based on Extracellular Matrices for Cartilage Tissue Engineering. Tissue Engineering - Part B:

Reviews, 25(3), 202-224. https://doi.org/10.1089/ten.teb.2018.0245

Document status and date:

Published: 01/06/2019

DOI:

10.1089/ten.teb.2018.0245

Document Version:

Publisher's PDF, also known as Version of record

Document license:

Taverne

Please check the document version of this publication:

- A submitted manuscript is the version of the article upon submission and before peer-review. There can be important differences between the submitted version and the official published version of record.

People interested in the research are advised to contact the author for the final version of the publication, or visit the DOI to the publisher's website.

- The final author version and the galley proof are versions of the publication after peer review.

- The final published version features the final layout of the paper including the volume, issue and page numbers.

Link to publication

\footnotetext{
General rights rights.

- You may freely distribute the URL identifying the publication in the public portal. please follow below link for the End User Agreement:

www.umlib.nl/taverne-license

Take down policy

If you believe that this document breaches copyright please contact us at:

repository@maastrichtuniversity.nl

providing details and we will investigate your claim.
}

Copyright and moral rights for the publications made accessible in the public portal are retained by the authors and/or other copyright owners and it is a condition of accessing publications that users recognise and abide by the legal requirements associated with these

- Users may download and print one copy of any publication from the public portal for the purpose of private study or research.

- You may not further distribute the material or use it for any profit-making activity or commercial gain

If the publication is distributed under the terms of Article $25 \mathrm{fa}$ of the Dutch Copyright Act, indicated by the "Taverne" license above, 


\title{
Hybrid and Composite Scaffolds Based on Extracellular Matrices for Cartilage Tissue Engineering
}

\author{
Mohsen Setayeshmehr, MS, ${ }^{1-3}$ Ebrahim Esfandiari, MD, $\mathrm{PhD},{ }^{4}$ Mohammad Rafieinia, $\mathrm{PhD},{ }^{2}$ \\ Batool Hashemibeni, PhD, ${ }^{4}$ Asghar Taheri-Kafrani, PhD, ${ }^{5}$ Ali Samadikuchaksaraei, MD, PhD, 1,6 \\ David L. Kaplan, PhD, ${ }^{7}$ Lorenzo Moroni, PhD, ${ }^{3,8}$ and Mohammad T. Joghataei, PhD ${ }^{1,6}$
}

Cartilage consists of chondrocytes and a special extracellular matrix (ECM) having unique biochemical, biophysical, and biomechanical properties that play a critical role in the proliferation and differentiation of cells inherent to cartilage functions. Cartilage tissue engineering (CTE) requires recreating these microenvironmental physicochemical conditions to lead to chondrocyte differentiation from stem cells. ECM-derived hybrid scaffolds based on chondroitin sulfate, hyaluronic acid, collagen, and cartilage ECM analogs provide environments conducive to stem cell proliferation. In this review, we describe hybrid scaffolds based on these four cartilage ECM derivatives; we also categorize these scaffolds based on the methods used for their preparation. The use of hybrid scaffolds is increasing in CTE to address the complexity of cartilage tissue. Thus, a comprehensive review on the topic should be a useful guide for future research.

Keywords: cartilage, tissue engineering, hybrid scaffolds, extracellular matrix (ECM), ECM derivatives

\section{Impact Statement}

Scaffolds fabricated from extracellular matrix (ECM) derivatives are composed of conducive structures for cell attachment, proliferation, and differentiation, but generally do not have proper mechanical properties and load-bearing capacity. In contrast, scaffolds based on synthetic biomaterials demonstrate appropriate mechanical strength, but the absence of desirable biological properties is one of their main disadvantages. To integrate mechanical strength and biological cues, these ECM derivatives can be conjugated with synthetic biomaterials. Hence, hybrid scaffolds comprising both advantages of synthetic polymers and ECM derivatives can be considered a robust vehicle for tissue engineering applications.

\section{Introduction}

A RTICULAR CARTILAGE (AC) is a connective tissue comprising also the main component of joints' surface, which covers and protects bones. Cartilage is composed of specialized cells and extracellular matrix (ECM). ${ }^{1}$ Three major types of cartilaginous tissues are distinguished: hyaline cartilage, fibrocartilage, and elastic cartilage. The chemistry and the supramolecular structure of the matrices determine the biomechanical and functional properties of these three cartilage types. Hyaline cartilage is the most abundant and well characterized, found as $\mathrm{AC}$ on the surfaces of bones. ${ }^{2,3}$ AC can bear loads of up to around $20 \mathrm{MPa}$ during normal joint movements. ${ }^{1}$ The major macromolecular components of hyaline cartilage include collagen (COL) type II and $\mathrm{X}$, cartilage oligomeric matrix protein, and proteoglycans,

\footnotetext{
${ }^{1}$ Department of Tissue Engineering and Regenerative Medicine, Faculty of Advanced Technologies in Medicine, Iran University of Medical Sciences (IUMS), Tehran, Iran.

${ }^{2}$ Biomaterials Nanotechnology and Tissue Engineering Group, Department of Advanced Medical Technology, Isfahan University of Medical Sciences, Isfahan, Iran.

${ }^{3}$ MERLN Institute for Technology Inspired Regenerative Medicine, Complex Tissue Regeneration, Maastricht University, Maastricht, The Netherlands.

${ }_{5}^{4}$ Department of Anatomical Sciences and Molecular Biology, Faculty of Medicine, Isfahan University of Medical Sciences, Isfahan, Iran.

${ }^{5}$ Department of Biotechnology, Faculty of Advanced Sciences and Technologies, University of Isfahan, Isfahan, Iran.

${ }^{6}$ Cellular and Molecular Research Center, Iran University of Medical Sciences (IUMS), Tehran, Iran.

${ }^{7}$ Department of Biomedical Engineering, Tufts University, Medford, Massachusetts.

${ }^{8}$ CNR Nanotec-Institute of Nanotechnology, c/o Campus Ecotekne, Università del Salento, Lecce, Italy.
} 
among which aggrecan (ACAN) is the major component. Collagens and proteoglycans play critical roles in maintaining cartilage ECM structure. The mechanical strength of the different zones of $\mathrm{AC}$ is defined by changes in chemistry and biomechanical cues of the macromolecular components. ${ }^{3-5}$ Mechanical characteristics and load-bearing ability of AC are related to and optimized by the arrangement of COL fiber organization, proteoglycan content, and chondrocyte shape. ${ }^{6}$ The ECM also forms a niche for stem cells (SCs) and provides biochemical and physical signals to control their proliferation. ${ }^{7}$ Recent studies demonstrated that SCs necessitate a particular tissue niche for proliferation and differentiation. ${ }^{8}$ In addition to the biochemical environment, mechanical cues of the ECM, such as stiffness, also impact SC lineage differentiation. ${ }^{9}$ Soft, medium, and hard matrices can induce mesenchymal stromal cells (MSCs) to differentiate into neurons, myocytes, and osteoblasts, respectively. ${ }^{10}$ MSCs are site regulated; they secrete different factors to modulate tissue protection and regeneration by interacting with their niche microenvironment mediated by ECM components. ${ }^{11}$

Recent studies demonstrate that chondrocytes sense physical cues such as receptor/ligand density, rigidity/softness, and shape (dimensionality) of the ECM surface by mechanoreceptors. In response to these cues, the cells modulate the organization of the cytoskeleton, extracellular adhesion sites, and cell shape. ${ }^{12,13}$ Studies performed on artificial scaffolds, such as hydrogels, porous/fibrous scaffolds, and ECM-based constructs, demonstrated that SCs expand and differentiate, faster on the softer materials such as COL than stiffer substrates such as chitosan (CHSN). ${ }^{14,15}$ One approach to create three-dimensional (3D) structures that mimic the cartilage natural niche is to utilize scaffolds based on cartilage ECM, but generally these scaffolds have lower mechanical strength and suffer from lot-to-lot variations. ${ }^{16}$ Synthetic and polymeric materials, including poly(DL-lactic-co-glycolic acid) (PLGA), poly( $\varepsilon$-caprolactone) (PCL), poly(D,L-lactic acid) (PLA) and their copolymers, poly vinyl alcohol (PVA) and also methacrylamide (MA) modification, have been used to fabricate scaffolds for AC replacement and to serve as cell transplantation vehicle for tissue engineering (TE). ${ }^{17-20}$ Synthetic polymeric scaffolds allow for good control of mechanical properties, but suffer from a lack of biological properties. These biomaterials are hydrophobic, lack functional adhesion sites and cell recognition signals, and therefore must be modified before cell seeding. ${ }^{21}$ In contrast, scaffolds manufactured from ECM components contain surface structures conducive to cell growth. ${ }^{22}$ Hence, hybrid scaffolds comprising both advantages of synthetic polymers and ECM derivatives can be considered a strong vehicle for TE applications. ${ }^{23}$

Although other reviews related to cartilage ECM derivatives have been published already, this review focuses on cartilage ECM-derived hybrid and composite scaffolds, prepared and used specifically for cartilage tissue engineering (CTE). Four sections describe (1) COL and COLbased scaffolds, (2) hyaluronic acid (HA) and HA-based scaffolds, (3) chondroitin sulfate (CS) and CS-based scaffolds, and (4) cartilage ECM analogs (cECMa) and cECMa-based scaffolds. The fifth section reviews the different hybrid scaffold processing approaches, and in the sixth section, results from ECM-based scaffolds are discussed in detail.

\section{Hybrid and Composite Scaffolds for CTE}

\section{COL-based scaffolds}

Collagens can be considered the most important proteins of connective tissue in mammals and also the most abundant proteins in their body. ${ }^{24}$ About 30 different forms of COL have been defined according to the amino acid sequences and the structures that they are arranged into. The three most common types of collagens are type II, type I, and type X, in hyaline cartilage, fibrocartilage, and hypertrophic cartilage, respectively. ${ }^{25}$ As abundant and biocompatible natural products, collagens have been thoroughly investigated and are widely used as TE scaffolds. ${ }^{26}$ Important drawbacks of collagens are, however, inferior mechanical strength and quick degradation, compromising their use for CTE applications. These disadvantages can be partially rectified by crosslinking $^{27}$ collagens with natural and synthetic polymers to afford blends and composite materials of superior properties. $^{28}$ For instance, blend scaffolds composed of COL crosslinked with $\mathrm{CHSN}$ have improved mechanical strength than unmodified COL. ${ }^{29}$ A mixture of COL and CHSN exhibits higher mechanical strength because of their miscibility, hydrogen bonding, and electrostatic interactions that reinforce the composite. ${ }^{30}$ Partial hydrolysis of COL leads to gelatin (GEL) production. Despite its similarity to chemical COL composition, it lacks antigenicity and immunogenicity. GEL has been used for cartilage, bone, and nerve TE. ${ }^{31}$ Hybrid scaffolds composed of COL and synthetic materials, such as PLA, PLGA, PVA, PCL, MA, poly(ethylene glycol) (PEG), or natural biomaterials, including $\mathrm{CHSN}$, agarose (AGR), alginate (ALG), elastin, silk fibroin (SF), and others that have been used for CTE, are listed in Table 1.

\section{HA-based scaffolds}

Hyaluronic acid (HA) is a key component in the ECM of cartilage. It is an anionic glycosaminoglycan (GAG) of up to $4000 \mathrm{kDa}$ with hydrogel-like properties. ${ }^{63,77-80}$ Elasticity and viscosity of the synovial fluid and shock absorbance capacity in articular joints are due to HA. HA is the primary ligand of the CD44 receptor, and several functions of the CD44 receptor are mediated through interaction with HA. ${ }^{81,82}$ Crosslinking is the most common modification of HA, to form hydrogels for TE applications. The methacrylation is one of the frequently used technique for modification of HA hydrogels. Changing the methacrylation percentage directly effects on the crosslinking density and stiffness of the hydrogel matrix. ${ }^{83} \mathrm{HA}$ has also been chemically functionalized for the attachment of reporter groups for drug delivery systems. Composite materials of HA with natural and synthetic polymers were developed into biomimetic scaffolds with ability of enhancing wound healing and angiogenesis. ${ }^{84}$ Hybrid and composite scaffolds composed of HA and synthetic materials (PLGA, PVA, PEG, and MA) and with natural biomaterials (CHSN, fibrin, AGR, ALG, and dextran) have been used for CTE (Table 2).

\section{CS-based scaffolds}

CS is a GAG, a long unbranched and polar polysaccharide consisting of amino sugars and sugar acids. CS plays a critical role as a main component of the ECM in cartilage functions. $^{125}$ The ECM regulates metabolism as well as 


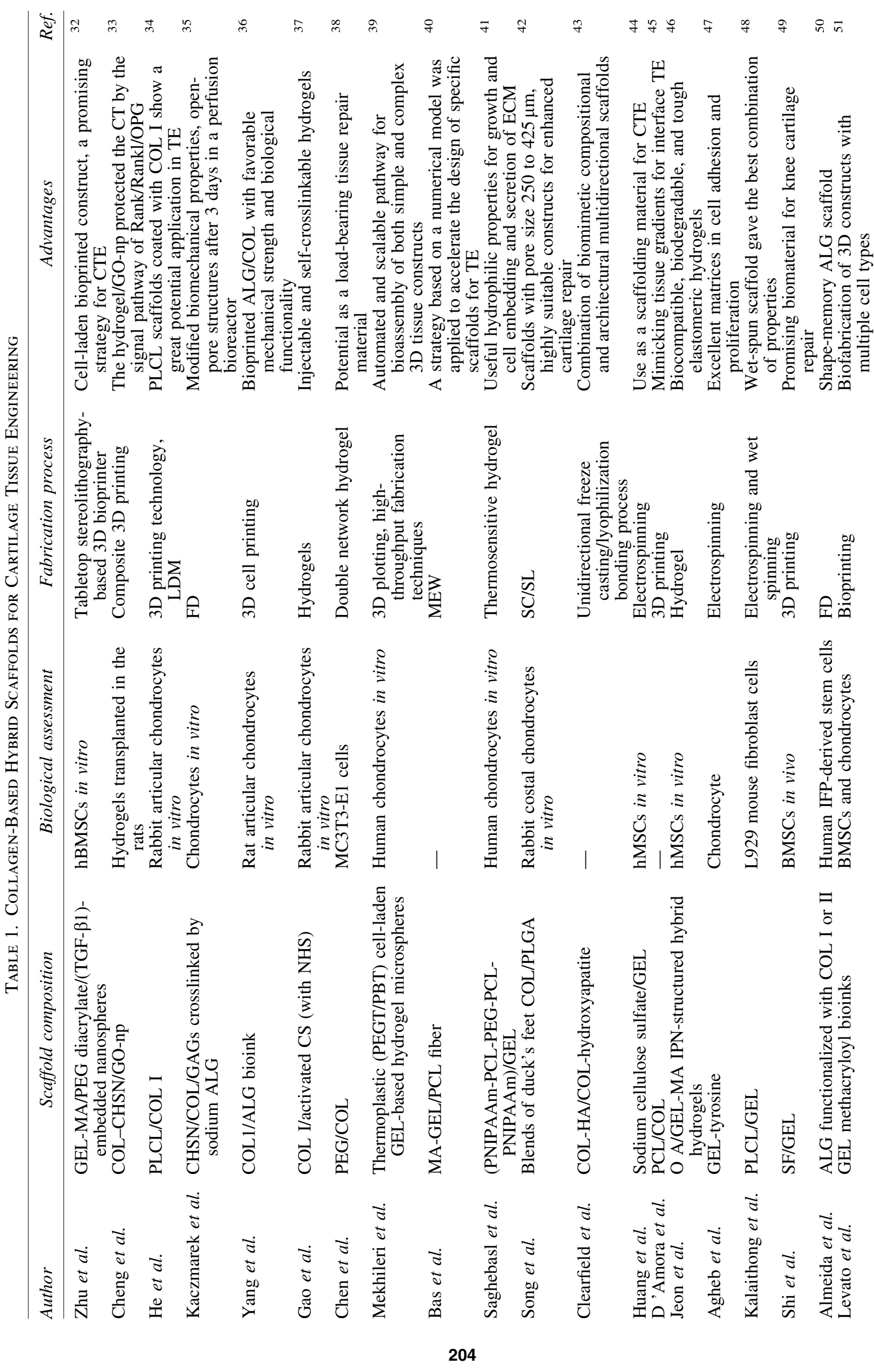




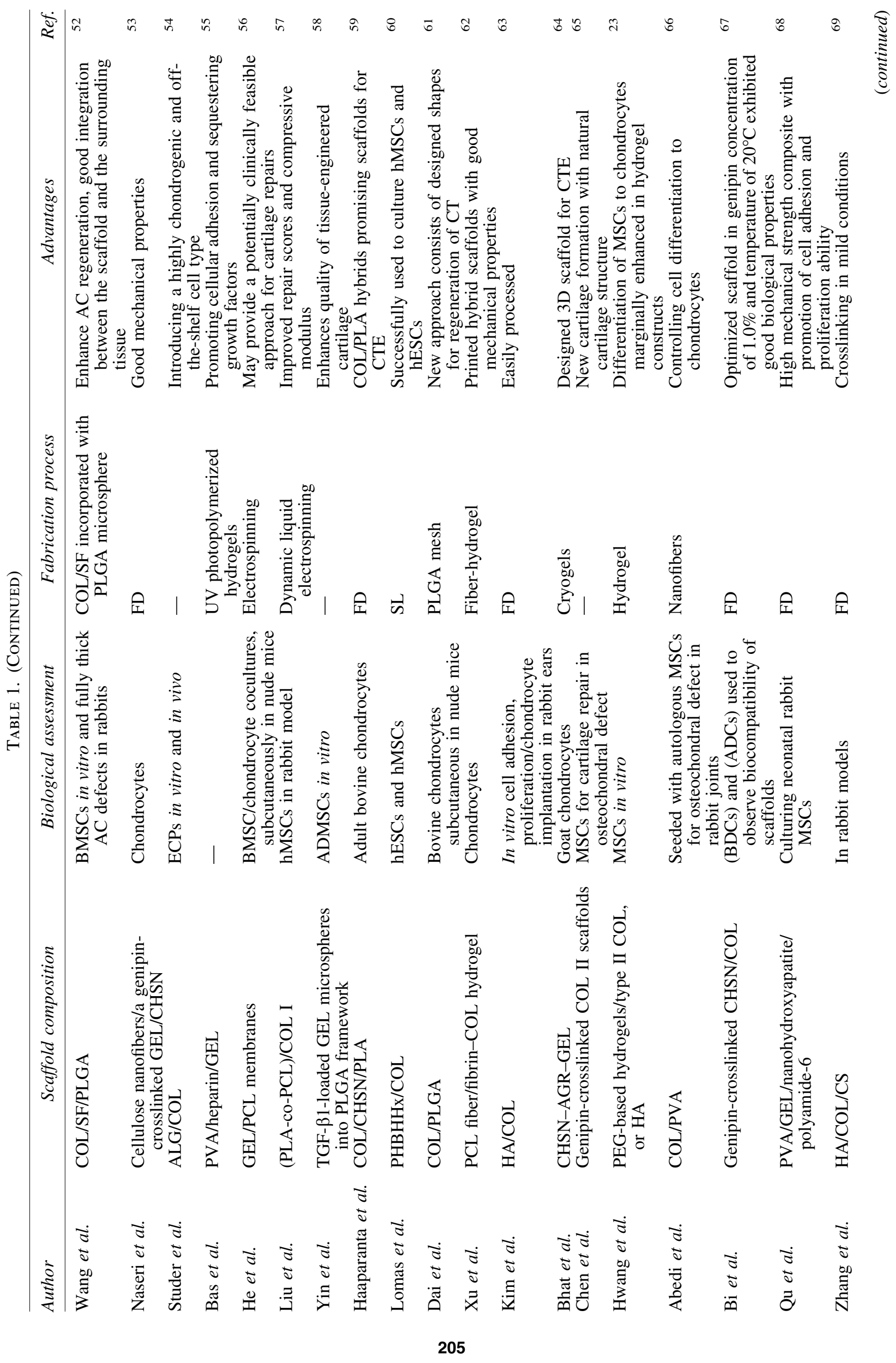




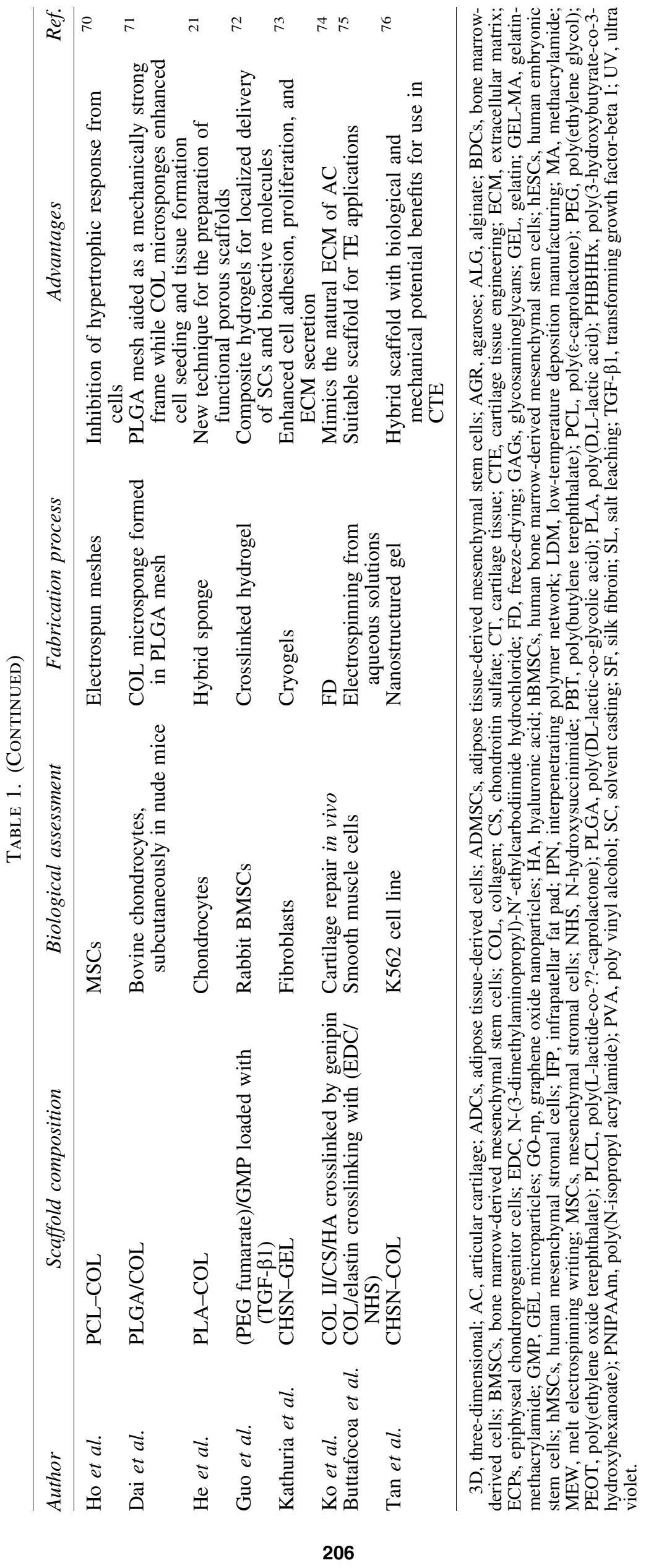




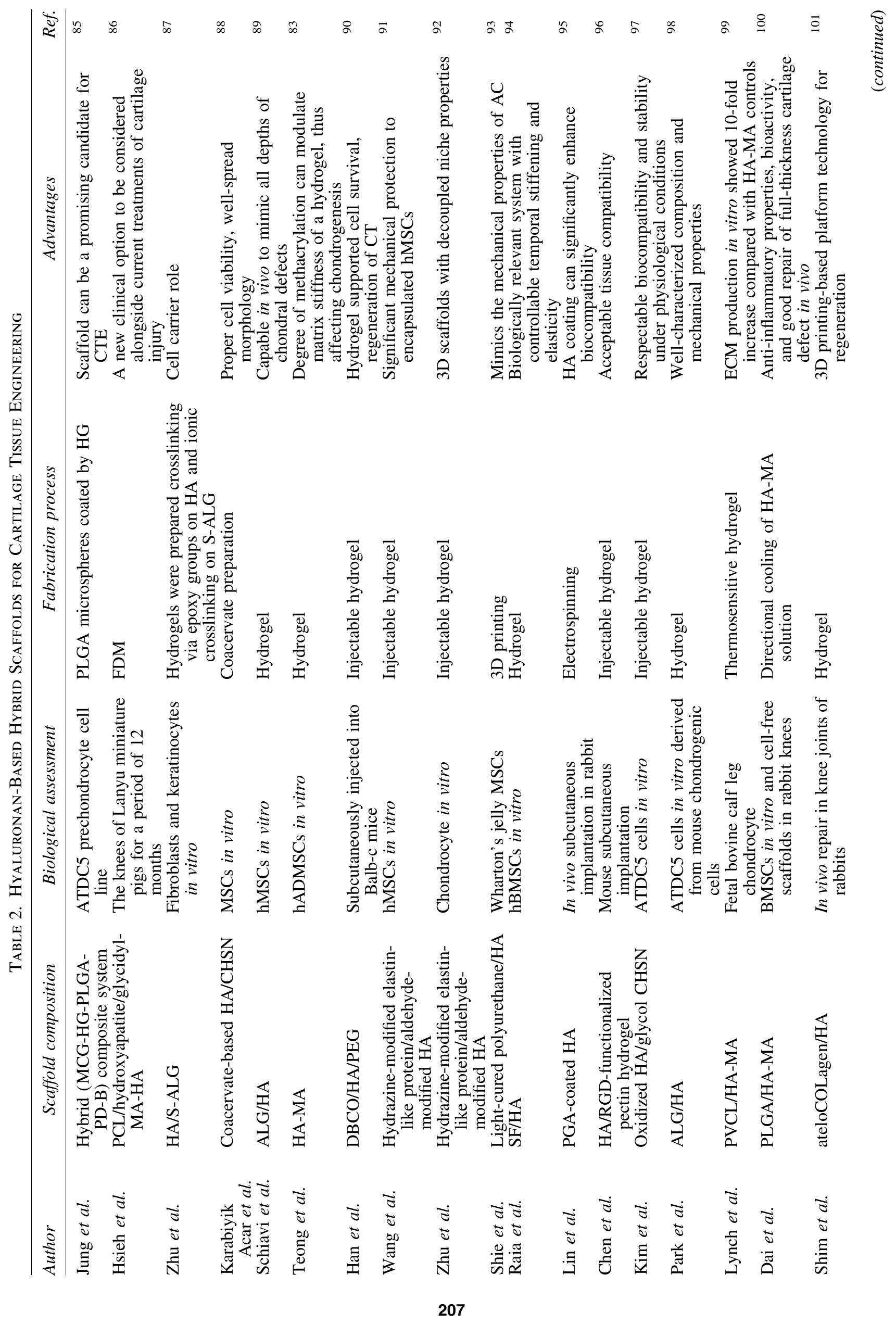




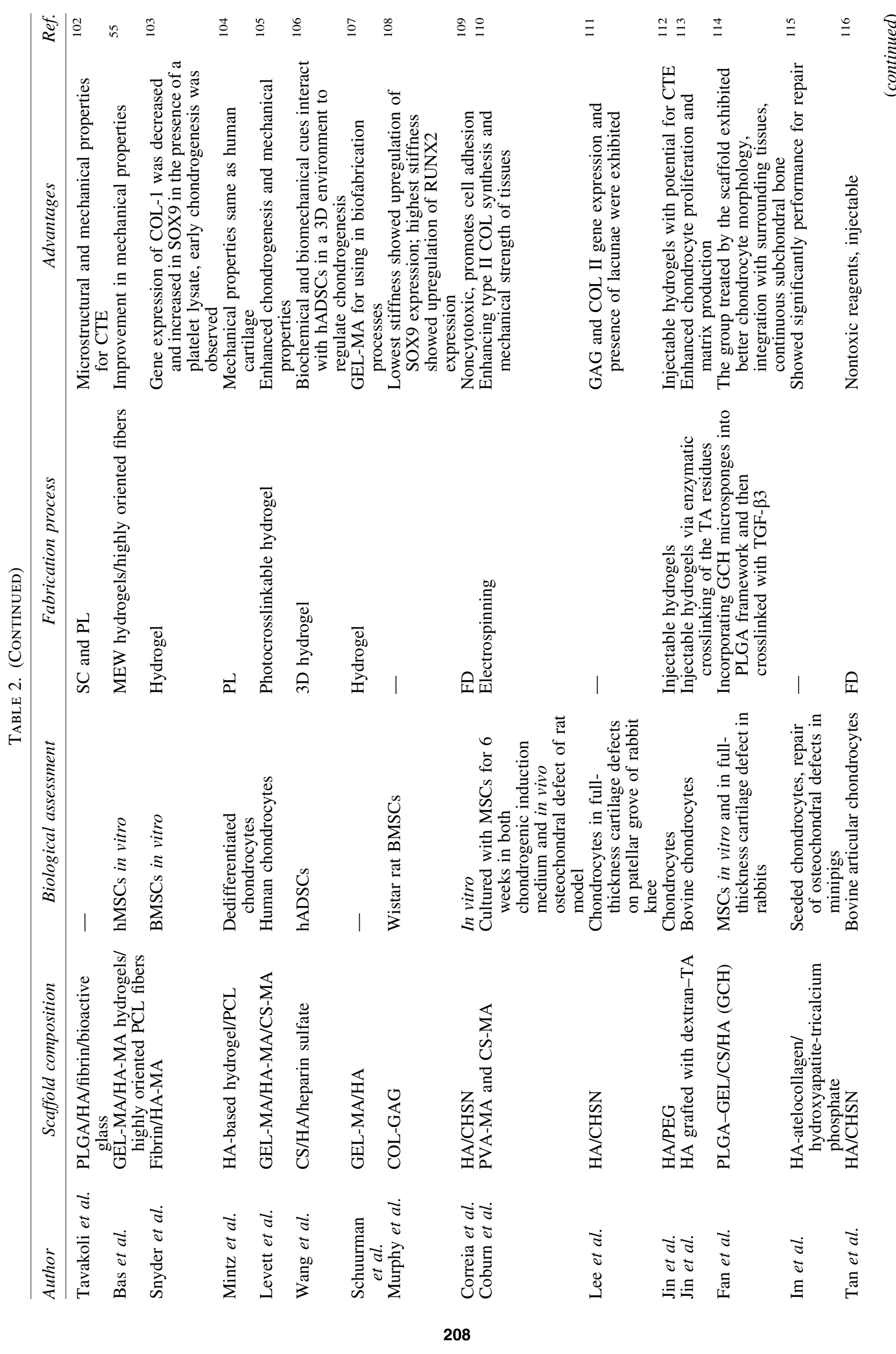




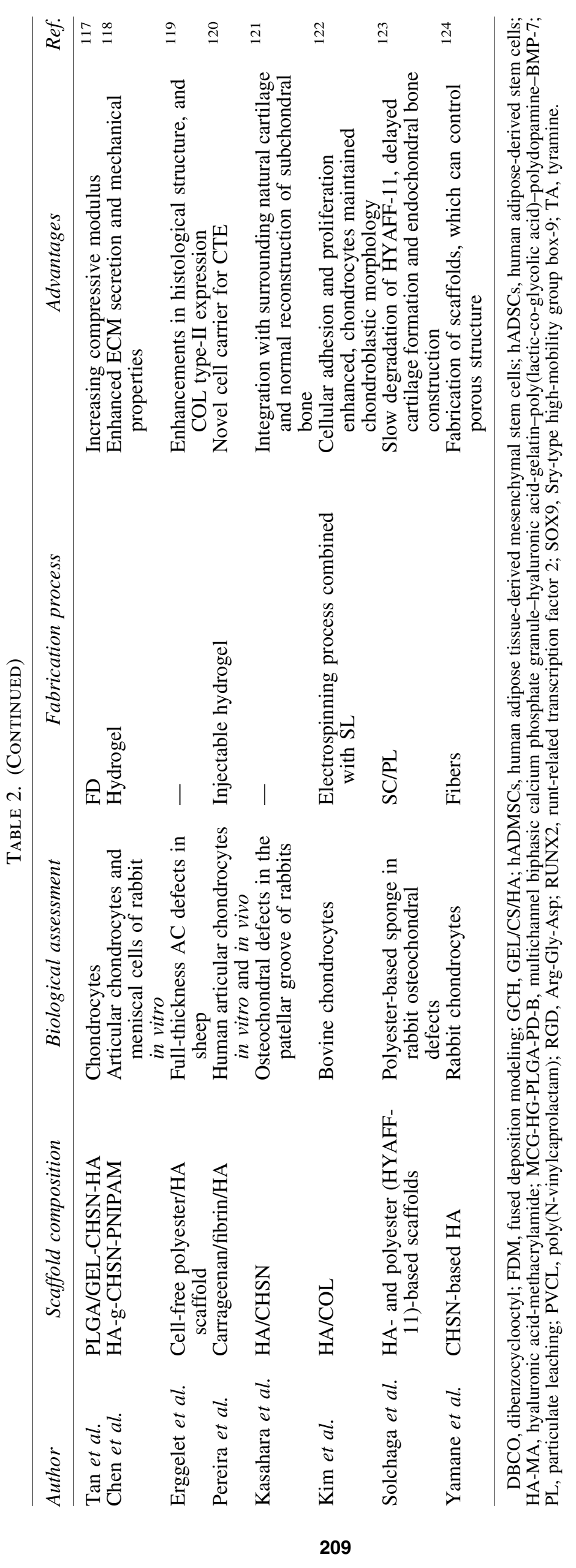


gene expression and stimulates proliferation and differentiation of chondrocytes. ${ }^{126}$ The biological activities of CS make it an ideal biomaterial for CTE. The chondroprotective action of CS can be explained by the stimulation of the anabolic progression of cartilage metabolism, and its antiinflammatory action, delaying numerous inflammationinduced catabolic processes in the tissue. ${ }^{127,128}$ The inclusion of CS in composite scaffolds improves their mechanical properties and compressive strength by interacting with cell surface receptors to regulate chondrocyte behavior. ${ }^{129} \mathrm{Hy}-$ brid scaffolds containing CS and synthetic as well as natural polymers have been used for CTE and are listed in Table 3.

\section{ECM analog-based scaffolds}

The use of decellularized ECM scaffolds and tissues is speedily expanding in TE. ${ }^{146}$ There are many reasons for utilization of ECM-based materials in TE applications, including promotion of SC recruitment, cell infiltration, and differentiation without the need of additional biological factors. Cartilaginous ECM may be innovative in orthopedic medicine because of its chondroinductive potential, particularly in hydrogel-based systems. ${ }^{147}$ The potential of ECM-based scaffolds to retain growth factors such as transforming growth factor-beta 1 (TGF- $\beta 1$ ), fibroblast growth factor, and insulin-like growth factor is one of the major advantages of utilizing these materials as a scaffold. ${ }^{148}$ However, the inferior mechanical properties of scaffolds composed completely of natural materials compared with synthetic materials are a major disadvantage for load-bearing tissue applications. Therefore, combinations of these ECM-based materials with suitable synthetic materials can be of advantage for CTE. ${ }^{147}$ Hybrid scaffolds composed of ECM analogs and synthetic materials, as well as natural biomaterials, have been used for CTE and are listed in Table 4.

\section{Hybrid Scaffold Processing Approaches}

A multitude of porous ECM-derived hybrid scaffolds and scaffold processing approaches have been utilized in CTE. The most frequently used types are discussed below.

\section{Fibrous scaffolds}

Electrospinning of natural and synthetic biomaterials is a promising technique to produce fibrous scaffolds for TE applications. $^{102}$ The combination of synthetic polymeric materials and natural components such as COL could increase cell attachment while presenting ideal mechanical properties for TE applications. ${ }^{56}$ PCL-COL electrospun meshes were used in autologous chondrocyte implantation as an innovative substitute to conventional grafts, which was the first try to design a mechanically enhanced cartilage resurfacing membrane composed of strong PCL mesh with bioactive COL. MSCs adhered on the surface of the mesh after seeding. More importantly, the mesh induced MSC differentiation into chondrocytes and inhibited a cellular hypertrophic response. This study showed the impact of the use of PCL-COL hybrid mesh as a cartilage patch and showed the importance of incorporation of the ECM-derived component COL into the synthetic PCL. ${ }^{163}$ In a similar study, oriented PLA-co-PCL/COL I nanofiber yarn meshes were fabricated by dynamic liquid electrospinning and aided as a skeleton for a freeze-dried (FD) COL I/HA chondral phase to improve the mechanical properties of the scaffolds. In vitro and in vivo results demonstrated that the hybrid constructs allowed cell infiltration similar to sponge scaffolds, and repaired the rabbit model osteochondral defects with improved mechanical properties of the newly engineered cartilage. ${ }^{57}$ In another approach, COL/PVA nanofiber scaffolds were prepared and seeded with autologous MSCs to repair osteochondral defects of rabbit joints. The hybrid scaffolds induced higher chondrocyte morphology and new cartilage formation compared with the control defect without any treatment. The results showed that the nanofibrous COL/ PVA scaffolds provide a supportive environment for cartilage tissue (CT) regeneration over 12 weeks. The histological results demonstrated that the COL/PVA group had better cartilage repair, more new matrix formation, and continuous subchondral bone compared with the control group. ${ }^{66}$ In a further approach, oriented PCL fibers were fabricated by melt electrospinning writing $(\mathrm{MEW})$ and combined with gelatin-methacrylamide (GEL-MA) and GEL-MA/HA-MA hydrogels to produce fiber-reinforced GEL-MA/HA-MA composites with enhanced mechanical properties. The results demonstrate that reinforcement of hydrogels with fibers leads to increases in the mechanical properties of the hybrid construct. ${ }^{55}$ In vitro and in vivo studies on a sandwich model of electrospun GEL/PCL membranes, seeded with MSC/chondrocyte cocultures, were performed. To engineer the sandwich model, a GEL/PCL mesh was placed at the bottom of a well and seeded with cell suspension. A second mesh was then stacked on top of the first sheet, followed by cell seeding. The stacking was repeated until ten sheets. After implantation of the sandwich constructs 12 weeks subcutaneously into nude mice, histological analysis, GAG assay, and mechanical property measurement confirmed the formation of mature cartilage-like tissue. The strategy indicated that designed constructs were suitable for SC-based CTE. The constructs showed white appearance, flexibility, and a well-distributed synthesized neomatrix typical of cartilage. ${ }^{56}$

Yamane et al. ${ }^{164}$ developed hybrid fibers based on CHSN and CHSN-HA by wet spinning. Articular chondrocytes from rabbits were cultured in the sheets of CHSN- and HAbased hybrid fibers. The fibers exhibited potential as an appropriate biomaterial for cartilaginous tissue scaffolds. ${ }^{124}$ In a similar study, 3D scaffolds based on novel CHSN-based HA hybrid polymer fibers, which could control porous structure, were fabricated by wet spinning. The results showed that cell adhesion, proliferation, and synthesis of ACAN were higher in the CHSN-HA hybrid fiber than in the CHSN-only group. ${ }^{164}$

Chondroinductive nanofiber composites of PVA-MA and chondroitin sulfate-methacrylamide (CS-MA) were synthesized and used for AC repair. MSCs cultured on these scaffolds were shown to support an increase in cell proliferation, ECM production, and cartilage-specific gene expression (Fig. 1) in vitro as well as in vivo. ${ }^{165}$

ECM-coated scaffolds display the advantages of both natural and synthetic components. Polymeric scaffolds provide the strength and robustness to support tissue growth, while the ECM coating acts in bioactive signal providing needed cues for differentiation. ${ }^{160}$ Electrospun PCL microfibers 


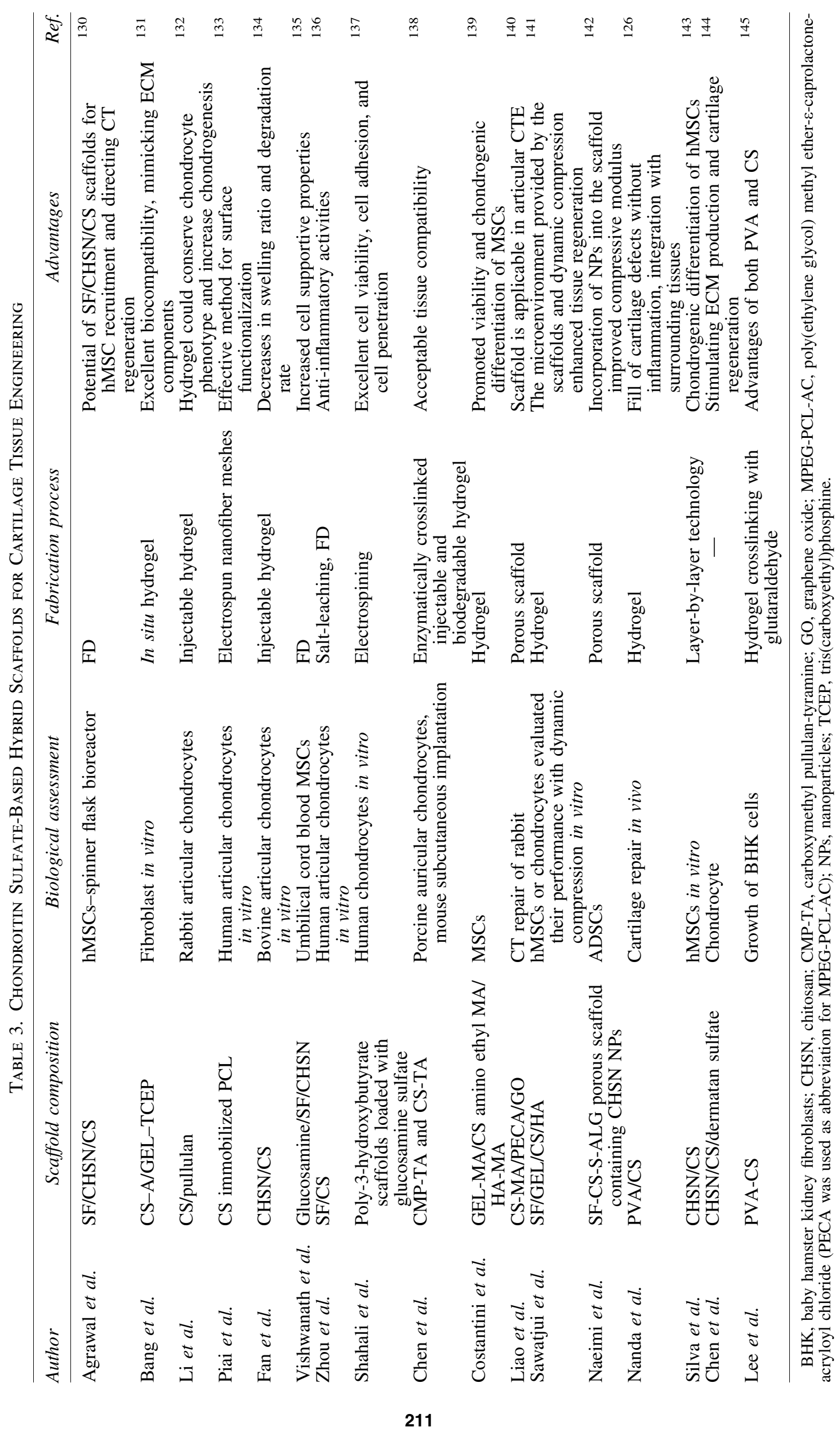




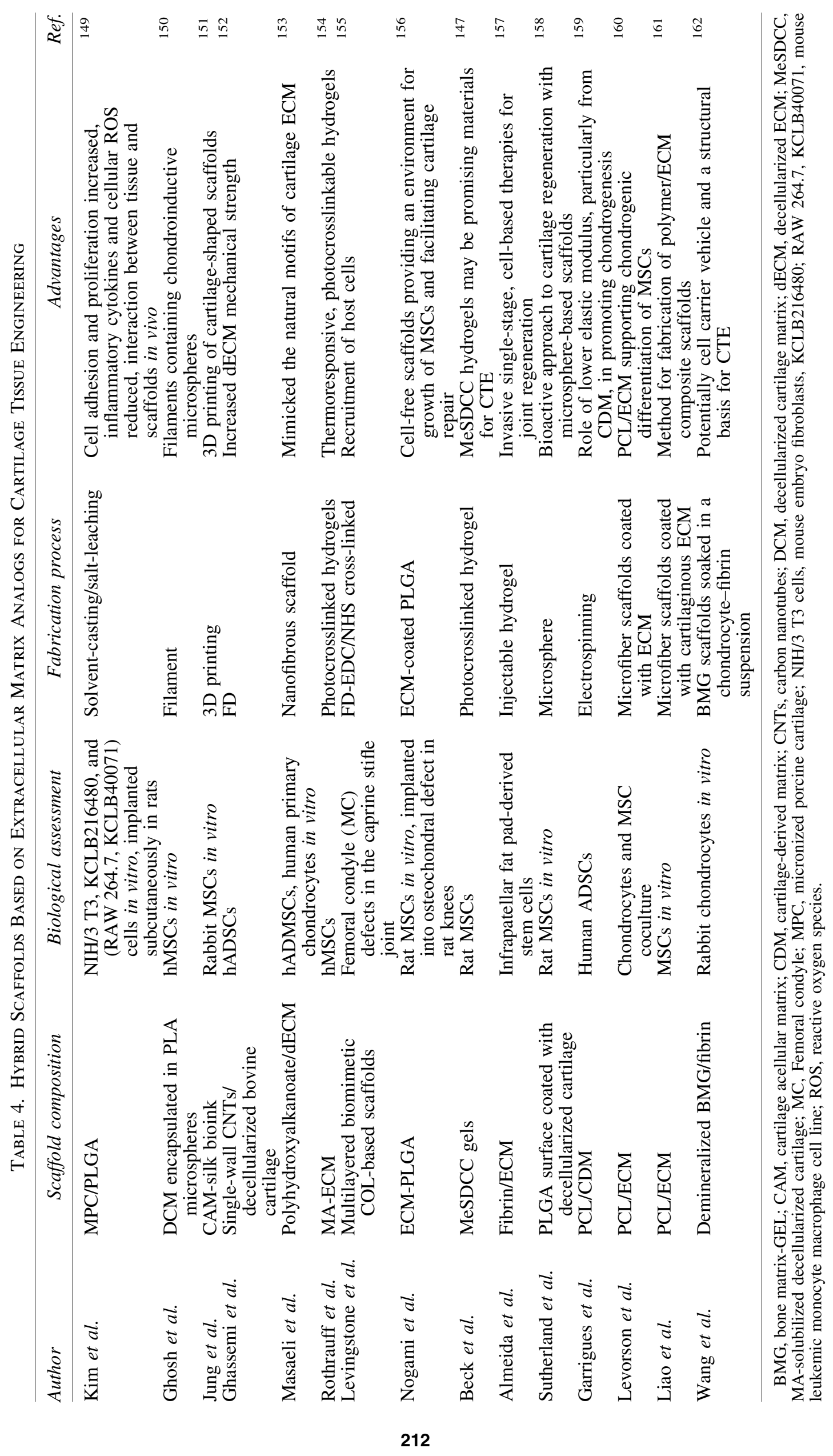




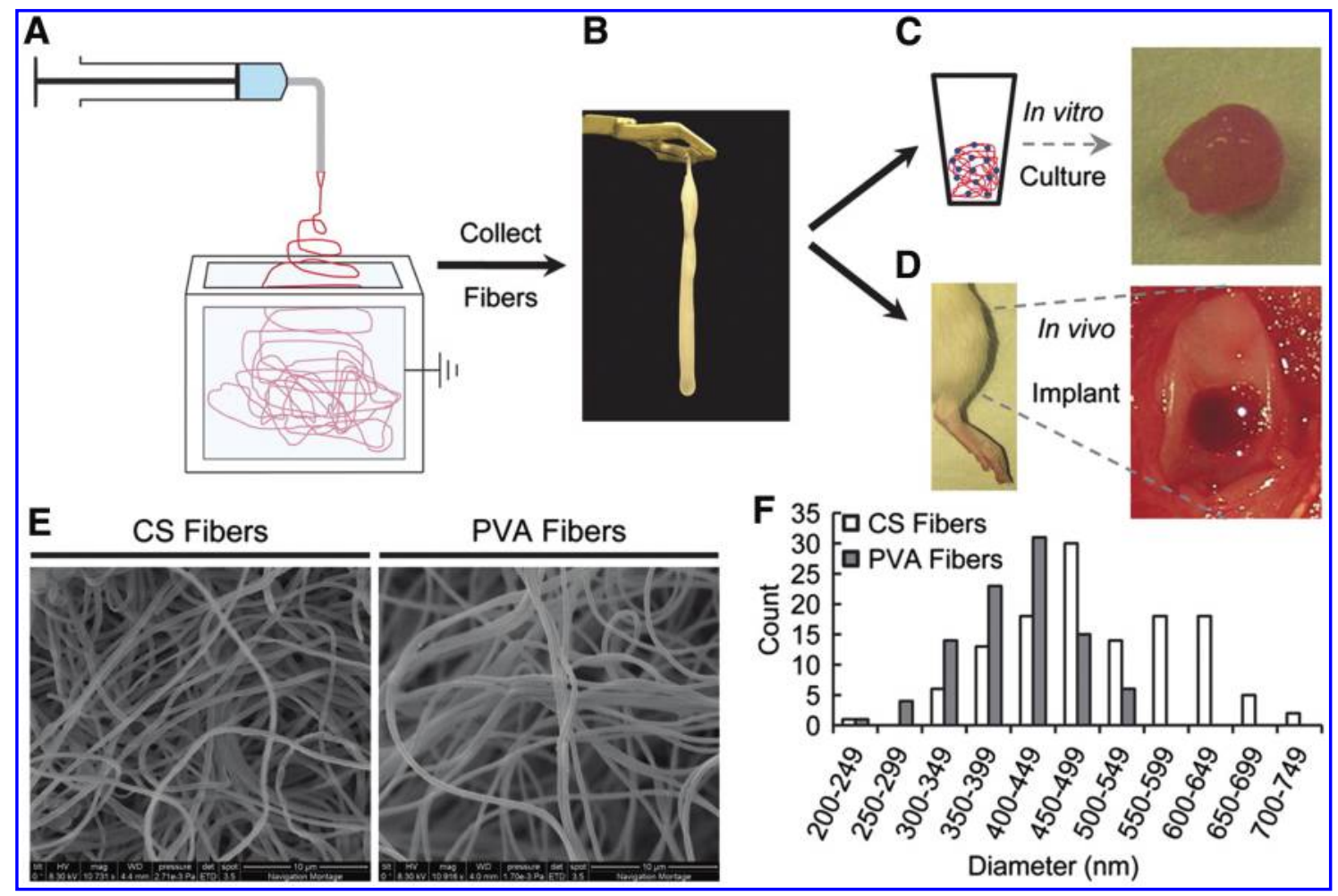

FIG. 1. (A, B) Nanofiber composites of PVA-MA and CS-MA were synthesized using electrospinning system in which the nanofibers were collected into an ethanol bath. (C) In vitro chondrogenesis of MSCs was performed over 42 days. (D) Nanofibers were implanted into osteochondral defects in the rat hind limbs for 6 weeks. (E) Scanning electron microscopy imaging showed the morphology and (F) size distribution of the fibers. ${ }^{165} \mathrm{CS}$, chondroitin sulfate; MA, methacrylamide; MSCs, mesenchymal stromal cells; PVA, poly vinyl alcohol. Reprinted with permission from Coburn et al. ${ }^{165}$ Color images are available online.

were coated with cartilaginous ECM to fabricate PCL/ ECM composite scaffolds. Briefly, chondrocytes were cultured in a flow perfusion bioreactor, and then, the cellular constructs were decellularized. The composite scaffolds in the presence of TGF- $\beta 1$ exposure showed upregulation of ACAN and COL II gene expression. ${ }^{161}$ In a similar approach, coculture of chondrocytes and MSCs on electrospun fibrous scaffolds was performed to produce polymer/ECM hybrid constructs. The results indicated the capacity of cocultures to deposit cartilaginous matrix within a polymeric scaffold. Thus, cocultures of MSCs and chondrocytes can be used to reduce the needed chondrocytes to fabricate polymer/ECM hybrid scaffolds. ${ }^{160}$ An innovative technique was performed to fabricate PCL and PCL/cartilage-derived matrix scaffolds by the serial collection of 60 electrospun single-layer scaffolds, which were then seeded with human adiposederived stem cells (hADSCs). The results indicated that multilayer hybrid constructs improved homogeneous cell seeding and showed chondrogenesis-related bioactivity. ${ }^{159}$ Recent studies demonstrated that electrospinning can produce fibrous scaffolds with a high surface/volume ratio, resembling the natural ECM pore structure, thus useful in terms of cell adhesion, proliferation, and differentiation. To improve cell-scaffold interactions, a range of natural and synthetic biomaterials can be blended into the fibrous scaffolds. In view of the fact that the biodegradation rate of scaffolds can influence cell behavior and the following tissue regeneration, a proper biodegradation rate of the hybrid me- shes can also be produced to match and control the rate of tissue regeneration.

\section{Hydrogel scaffolds}

Hydrogels are composed of hydrophilic polymer chains with natural or synthetic origin. They offer many advantages, including biodegradability, easy processing, minimally invasive delivery manner, and modulating ability by regulation of crosslink density. For these reasons, hydrogels have been widely used in TE application and especially in CTE. ${ }^{79} \mathrm{COL}$ is one of the most common ECM derivatives used for culturing cells in vitro. COL can be reconstructed to form hydrogel to mimic the connective tissue in vitro. $\mathrm{Nu}$ merous ECM-like composites that combine 3D COL hydrogels with synthetic and natural polymers have been examined. $^{76}$ Hybrid gel matrices composed of COL and CHSN had been examined for their capacity to regulate cellular activity. The K562 (a human hematopoietic cell line) cells were cultured in 3D gels to examine cell proliferation and differentiation. ${ }^{76}$ In completion of the previous studies, elastic cryogels composed of CHSN-GEL were prepared via crosslinking with glutaraldehyde. Hybrid cryogels exhibited efficient cell adherence, proliferation, and ECM deposition by culturing a fibroblast cell line (Cos7). The results showed the potential of the hybrid hydrogel for TE applications. ${ }^{73}$ To achieve proper biomechanical and biological properties, researchers tried to fabricate scaffolds based on an optimized ratio of polymer solutions (CHSN, 
Aga, and GEL) and glutaraldehyde as the crosslinker, via cryogelation technology with incubation at subzero temperature. The fabricated scaffolds showed proper biodegradation, mechanical, and biological properties for effective cell interaction in subsequent tissue development. In vivo biocompatibility examination of the scaffolds suggested the potential of these cryogels as a 3D scaffold for CTE. ${ }^{166}$ Human chondrocytes were encapsulated in GEL-MA-based hydrogels, and combined with small amounts of photocrosslinkable CS-MA and HA-MA. According to the results, the incorporation of HA-MA to GEL-MA resulted in further round cell morphologies, improved chondrogenesis, and increased synthesized neomatrix throughout the hydrogel. As a result, the compressive modulus of the hydrogel containing HA-MA and CS-MA increased to $114 \mathrm{kPa}$ compared with the control GEL-MA $(26 \mathrm{kPa})$ after 8 weeks of culture. ${ }^{105}$

Entrapment of ECM molecules within a synthetic hydrogel is ultimately the most comprehensive method to create hydrogels containing biological signals. The ultra violet (UV) photopolymerized PVA hydrogels were prepared via methacrylated functionalization, and the effects of incorporation of heparin and GEL within a PVA hydrogel were examined. ${ }^{167}$ Chen et al. advanced the novel double network PEG/COL, whose mechanical strength could be modified by changing the rigidity, molecular weight, and crosslinking density of the two components. Results indicated that the incorporation of COL significantly enhanced the strength and toughness of hydrogels. The resulting hydrogels could offer a proper environment for cell attachment and proliferation. ${ }^{38}$

Injectable hydrogels can be presented by minimally invasive procedures and activated by environmental conditions, including $\mathrm{pH}$, temperature, ultrasound, ionic strength, or electric fields, to undertake a shape compliant to the surrounding defect site. Moreover, biological cues such as cells and growth factors could be coinjected with the hydrogels. ${ }^{80}$ Injectable synthetic/ natural hydrogel composites containing oligo(PEG)-fumarate (OPF), and GEL microparticles (GMP), were synthesized. OPF/GMP TGF- $\beta 1$-loaded composites, hydrogel encapsulating rabbit MSCs, supported osteochondral tissue generation in rabbit osteochondral defects at 12 weeks. $^{72}$ Novel biodegradable, biocompatible, and tough elastomeric hybrid hydrogels based on photocrosslinkable GEL and ionically crosslinkable ALG were engineered. These hydrogels offer an exciting venue to investigate the effect of mechanical stimulation on SC proliferation and differentiation. ${ }^{46}$ In situ CS/GEL hydrogels were achieved by simple mixing of aqueous solutions of both GEL-tris(carboxyethyl)phosphine and CS-acrylate via click chemistry strategy. In vitro studies showed excellent biocompatibility and potential of the hydrogel in various biomedical applications, including TE and drug delivery. ${ }^{131}$

Various ECM derivative molecules, such as CS and HA, have been used as the 3D hydrogels to support SC chondrogenesis. However, because of the lack of proper mechanical properties and matrix stiffness, it is difficult to explain the relative contribution of matrix stiffness on $\mathrm{SC}$ fate using ECM derivative hydrogels. Improvement of mechanical properties of these hydrogels can occur by incorporation of polymeric biomaterials. ${ }^{106}$ Three major types of cartilage ECM derivatives, HA, CS, and heparan sulfate, were incorporated to fabricate biomimetic hybrid scaffolds. The degree of methacrylation of these ECM molecules was a key factor to produce ECM-based hydrogel scaffolds. To investigate the effects of mechanical and biochemical cues on chondrogenesis, ADSCs were encapsulated in different hydrogel compositions with various ECM derivative concentrations $[0.5 \%, 1.25 \%, 2.5 \%$, and $5 \%(\mathrm{w} / \mathrm{v})]$ and different matrix stiffnesses $(3,30$, and $90 \mathrm{kPa})$. The results indicated that the influence of matrix stiffness on chondrogenesis is dependent on the composition of hydrogels in a nonlinear manner. ${ }^{106}$ A chondrogenic hydrogel composed of fibrin/HA-MA seeded with MSCs was further evaluated. The results indicated that the hydrogel could be considered a proper vehicle for MSC delivery and chondrogenesis induction. ${ }^{103}$

Regarding the disadvantage of using crosslinking agents in biological systems, a novel biocompatible hybrid hydrogel was prepared by an oxidized HA/CHSN solution in the absence of a crosslinker. This composite hydrogel supported the survival of encapsulated bovine articular chondrocytes, which retained a chondrocytic morphology. ${ }^{116}$ Novel injectable mixtures were synthesized under physiological conditions with PEG vinylsulfone macromers and thiol functionalized HA, which were crosslinked via Michael addition. On mixing with chondrocytes, these hydrogels afforded a homogeneous distribution of cells. ${ }^{113}$ Another injectable hydrogel, using blending of thermoresponsive engineered proteins and a dynamic covalent crosslinking system, was fabricated. By mixing aldehyde-modified HA and hydrazine-modified elastin-like protein via dynamic covalent hydrazone bonds, hydrogel formation occurred. This hydrogel represented proper mechanical support to encapsulated human mesenchymal stromal cells (hMSCs) during injection. ${ }^{91}$ In a recently published study by Raia et al., ${ }^{94} \mathrm{HA}$ and SF were enzymatically crosslinked to fabricate biocompatible hydrogels with mechanical strength comparable with the native tissues. The SF proteins crosslinked via horseradish peroxidase (HRP) by formation of dityrosine bonds, and tyramine (TA)-substituted HA was synthesized by the same reactions. Consequently, HA was covalently crosslinked with silk to form a composite hydrogel (Fig. 2). The results show that synthesized hydrogel can provide a proper biologically system with controllable mechanical properties for TE applications. ${ }^{94}$ According to previous works, HA-MA with different degrees of methacrylation were synthesized. The degree of methacrylation modulated matrix stiffness of the hydrogels, therefore affecting the ability of hADSC chondrogenesis. ${ }^{83}$

PVA is one of the most studied polymers in biomedical application, because of its great biocompatibility in combination with a variety of appropriate biomechanical properties, swelling capacity, and crosslinking opportunities. Nanda et al. ${ }^{126}$ crosslinked the PVA-CS hydrogels with glutaraldehyde and used them as a scaffold in TE. ${ }^{144}$ Also, hydrogel scaffolds of PVA/CS were fabricated to imitate the ECM to provide an environment for improved AC cartilage repair in vivo. ${ }^{126}$ Recently, based on CS, enzymatically crosslinkable, injectable, minimally invasive, and biodegradable hydrogels have been described under physiological conditions. The hydrogels consisted of carboxymethyl pullulan-TA (CMP-TA) and CS-TA conjugates, which were enzymatically crosslinked by horseradish peroxidase and hydrogen peroxide. According to the results, hydrogels were cytocompatible. The CMP-TA/CS-TA composite hydrogels 


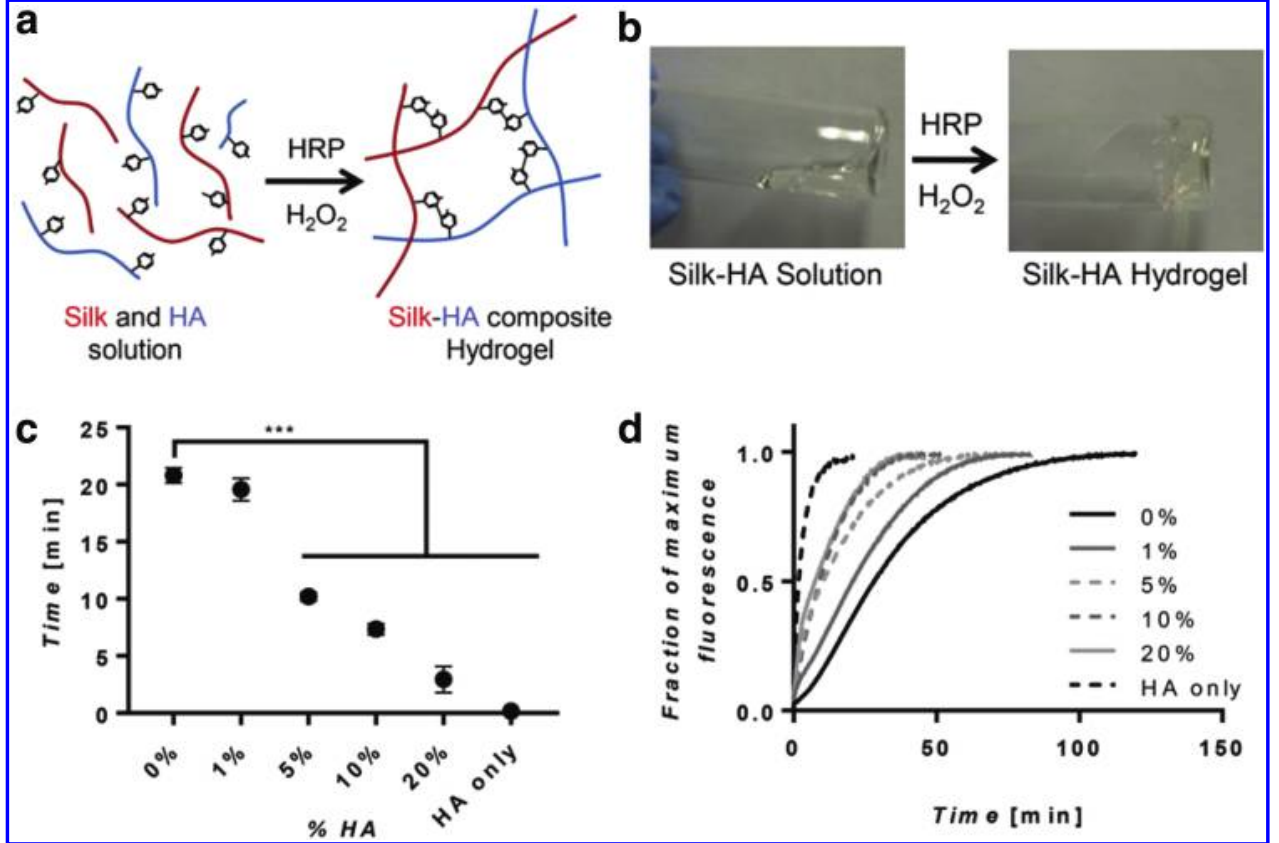

FIG. 2. (a) The silk-HA gel formation by covalent crosslinking of tyramine side chains on HA and tyrosine residues on silk. (b) The images of silk-HA gelation through a vial inversion test. (c) Vial inversion test results to evaluate gelation times. (d) The increasing of HA concentration affected crosslinking kinetics $(n=7) .{ }^{94}$ $(n=4, * * * p<0.001)$. Reprinted from Biomaterials, Raia et al. ${ }^{131}$ Enzymatically crosslinked silk-hyaluronic acid hydrogels, pp, 58-67, 2017, with permission from Elsevier. $\mathrm{HA}$, hyaluronic acid; $\mathrm{H}_{2} \mathrm{O}_{2}$, hydrogen peroxide. Color images are available online. enhanced cartilaginous ECM synthesis and cell chondrogenesis. ${ }^{138}$ Injectable and self-crosslinkable hydrogels were fabricated based on COL I and activated CS with Nhydroxysuccinimide by chemical and physical crosslinking without catalysts. The results suggest that these hydrogels were suitable candidates for applications in the fields of cell delivery and TE. ${ }^{37}$

Synthetic and natural compounds can be used to produce hydrogels taking advantage of their complementary and sometimes synergistic properties. Hydrogels consisting of ECM analogs can be similar to the natural cartilaginous ECM. Through the elastic network, they facilitate transport of nutrients and cellular metabolites, and they can be applied by simple, minimally invasive procedures to fill large and irregular complex defects. ${ }^{138,147}$ Similarly, injectable hydrogel based on methacrylated solubilized decellularized porcine cartilage was prepared by methacrylation and UV photocrosslinking modifications. In vitro studies showed that these hydrogels induced chondrogenic gene expression and new ECM cartilage formation with mechanical characteristics of native cartilage. ${ }^{147}$ In conclusion, hydrogels can be prepared from both synthetic and natural biomaterials. Synthetic biomaterials have the ability to control the chemical composition, mechanical properties, and biodegradation rate of the composite hydrogels. In contrast, hydrogels composed of natural biomaterials have the ability of providing biological cues and signals to enhance cell adhesion, proliferation, and differentiation. However, hybrid hydrogels composed of both synthetic/natural biomaterials can be an effective tool to achieve optimal cartilage regeneration.

\section{$3 D$ printing and biofabrication}

Additive manufacturing tools are based on the development of computer science and manufacturing technologies. The potential to fabricate highly complex constructs such as whole organs directly from a computer model is one of the main advantages of these approaches. ${ }^{168}$ Additive manufacturing offers a different potential to understand the structural constraints for TE scaffolds. On the contrary, it is also critical to develop the methods allowing efficient scaffold cellularization independent of shape and porosity. ${ }^{169}$ Frequently due to the absence of biological cues and hydrophobicity of the synthetic biomaterials used in scaffold fabrication by additive manufacturing, these scaffolds generally offer a limited environment for cell attachment and growth. Conversely, in those biofabrication techniques using living cells and biological materials, tissues are directly produced with ECM derivatives by controlling their 3D structures. However, inferior mechanical properties of such biofabricated constructs are considered a main limitation of these approaches. ${ }^{170}$ Recently, to overcome these restrictions, multihead deposition systems with the ability of bioprinting different row constituents consisting of synthetic and natural biomaterials, proteins, and cells have been developed. ${ }^{171} \mathrm{Xu}$ et al. ${ }^{62}$ tried to use inkjet-based cell printing in conjunction with electrospinning to fabricate constructs with improved mechanical properties. After spinning of a PCL layer, a rabbit chondrocyte/fibrinogen/COL solution was deposited onto the electrospun PCL fibrous layer. After gelation of the cell-printed solution, PCL was spun another time and followed by inkjet cell printing again. A final construct consisting of five layers of $1 \mathrm{~mm}$ thickness was fabricated. Cells showed $>80 \%$ viability a week after culture. ${ }^{62}$ Before using GEL-MA as a biomaterial for biofabrication purposes, several crosslinking parameters consisting of UV exposure time, polymer concentration, and thermal gelation before UV exposure were investigated to control the swelling and mechanical properties of the hydrogel. The opportunity to control mechanical properties, swelling behavior, and high cell compatibility and the ability to synthesize cartilaginous matrix make GEL-MA a suitable material for CTE. Results showed that when GEL-MA is combined with HA as a viscosity-enhancing additive, it could be printed into layered hydrogel structures. The results 
confirmed that the engineered constructs allow matching the natural functional variations in cartilage biomechanical properties. ${ }^{107}$ In a more recent approach, Visser et al. ${ }^{172}$ reinforced soft GEL-MA hydrogels with high porosity and a highly organized 3D-printed PCL network that was fabricated via the MEW technique. The mechanical properties of the gel/scaffold composites improved compared with microfiber scaffolds or hydrogels alone. Chondrocytes embedded in the hybrid construct were viable, and retained their round morphology and physiological behavior in vitro. ${ }^{172}$ A novel hybrid scaffold based on PLA/photopolymerizable cell-laden hydrogels has been established. A hydrogel precursor was prepared from a solution of MA-modified GEL and the photoinitiator Li-TPO-L in cell culture medium. The fabricated TE constructs merged both advantages, synthetic additive manufactured constructs and a natural hydrogel matrix. ${ }^{169}$ Recently, a bioink consisting of GEL-MA, CSamino ethyl-MA, and HA-MA was loaded with MSCs to fabricate 3D biomimetic hydrogel scaffolds for CTE. Two coaxial needles were used to establish a proper system to bioprint hybrid constructs with high cell viability, high cell density, and high bioprinting resolution. The results confirmed that this method is a valuable candidate for advanced CTE. ${ }^{139}$ By combining SF and GEL with MSCs and a specific-affinity peptide E7, a functionally and structurally improved scaffold was designed via an indirect 3D printing method. Briefly, The SF-GEL mixture solution was dispensed to a 3D computer-aided design mold. After decreasing the temperature to form the gel, the mold was dissolved, and the scaffold then crosslinked with genipin. The scaffold showed efficient recruiting capacity for MSCs and provided a mechanical support and proper microenvironment for proliferation, differentiation, and neocartilage tissue production. ${ }^{49}$ Fabrication of gradient structures has been made by using the layer-by-layer inherent fabrication of additive manufacturing technologies. Gradient functionalization with controlled geometry and porosity on the surface of an additive manufactured PCL scaffold was investigated. First, the surface of PCL scaffold was aminolysed using a continuous gradient of amine concentration; second, by using EDC reaction, a COL gradient was formed via protein grafting. The results showed that for the construction of $3 \mathrm{D}$ scaffolds with chemical gradients and controlled structural properties, a combination of surface modification and additive manufacturing is an appealing strategy. ${ }^{45} \mathrm{~A}$ tabletop stereolithographybased bioprinter has been used for a new cell-laden CT construct fabrication. The bioink was composed of GEL-MA, various concentrations of PEG diacrylate, 2hydroxy-4-(2-hydroxyethoxy)-2-methylpropiophenone as a photoinitiator, and TGF- $\beta 1$-embedded nanospheres (Fig. 3). Cell growth, viability, and chondrogenesis were explored to develop an optimized 3D-bioprinted construct for CTE. A significant increase in chondrocyte-specific gene expression on printed constructs containing TGF- $\beta 1$ nanospheres over 3 weeks showed that cell-laden bioprinting is a promising strategy for CTE. ${ }^{32}$ A bioprintable natural bioink based on cartilage acellular matrix (CAM) for bioprinting of irregular shape tissues has been developed. As a support of the CAM powder, SF was used because of its physical crosslinking ability and controllable viscosity. Bioprinting of a cartilage-shaped scaffold using this CAM-SF bioink has been done successfully. ${ }^{151}$ The results of in vitro culture showed that a printed CAM-SF construct provided better cell morphology and neomatrix synthesis from rabbit BMSCs compared with a printed PCL construct.

According to recently published articles, bioprinting approaches have shown great potential in CTE applications. However, several limitations are still remaining in achieving

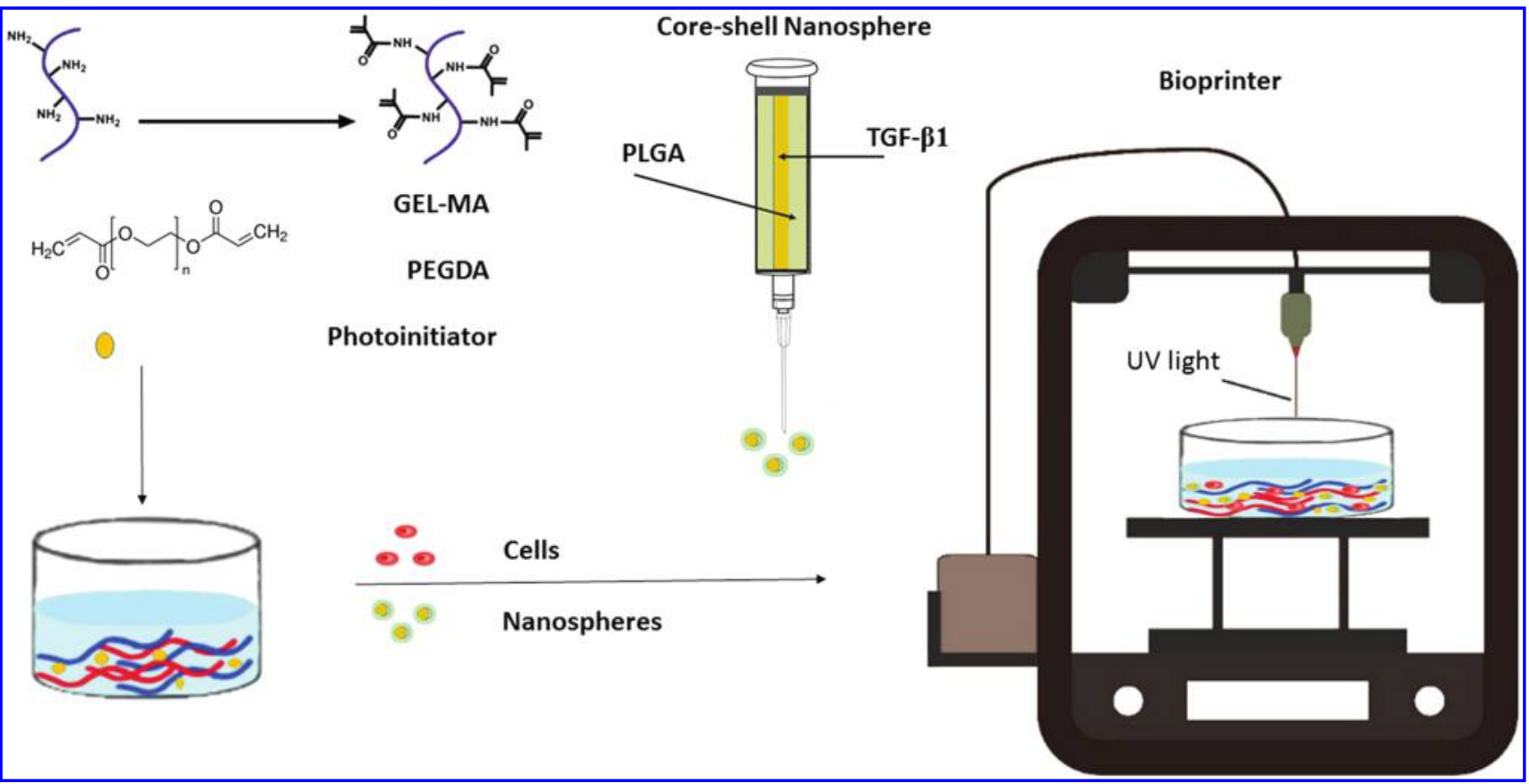

FIG. 3. Schematic design of cartilage construct printing via stereolithography-based bioprinter and synthesized bioink. ${ }^{32}$ GEL-MA, gelatin-methacrylamide; PEGDA, poly ethylene glycol diacrylate; PLGA, poly(DL-lactic-co-glycolic acid); TGF- $\beta 1$, transforming growth factor-beta 1 ; UV, ultra violet. Color images are available online. 
clinical applicability of these methods. The most challenging limitations are technical improvement and standardization, bioink formulation, and more closely mimicking the native cartilage mechanical properties. ${ }^{151}$ However, when different synthetic and natural biomaterials are associated within bioinks, they appear to mimic the cartilage microenvironment and to enhance cell viability and chondrogenic ability.

\section{Freeze-drying}

In FD, the material is frozen in a hydrogel shape and the water forms pockets of ice throughout the matrix. Consequently, these ice pockets are sublimated and removed under vacuum to produce the porous network. The size of pores can be controlled by the freezing temperature, thus producing porous structures with varying pore sizes and interconnectivities, due to varying heat transfer coefficients. Interconnected network composite scaffolds based on incorporating type II COL with CS and HA were fabricated utilizing chemical crosslinking and FD procedures, to mimic the native ECM of AC and upregulate cartilage ECM biosynthetic activities. ${ }^{74}$ The 3D porous hybrid scaffolds were prepared with incorporation of PLGA microspheres into GEL/CHSN/HA scaffolds and crosslinking with EDC, using the simple FD method. Cell culture confirmed that chondrocytes could secrete ECM and proliferate similar to the control (GEL/CHSN/HA scaffolds). ${ }^{117}$ The FD method was also used to prepare interconnected PVA/GEL/nanohydroxyapatite/polyamide- 6 bilayered hybrid scaffolds for in situ osteochondral defect repair. ${ }^{68}$ In another study, COL/ PLA, CHSN/PLA, and COL/CHSN/PLA hybrid scaffolds were fabricated via the combination of FD of the natural biomaterials COL and CHSN and PLA meshes. The 3D PLA meshes provided mechanical properties and the natural biomaterials mimicked the natural niche of chondrocytes. ${ }^{59}$ GEL scaffolds with interconnected pore structures and with good mechanical strength were fabricated using ice particulates and FD. Bovine articular chondrocytes were cultured on these scaffolds, for CT formation in vitro. ${ }^{173}$ The $3 \mathrm{D}$ porous scaffold-based cellulose nanofibers, stabilized using a genipin crosslinked matrix of Gel and CHSN, were prepared using FD. The results showed that the scaffolds have interconnected and homogenous pores, which supported chondrogenesis, thus highlighting the impact and efficiency of FD in the fabrication of hybrid scaffolds for CTE application of CHSN. ${ }^{53}$ Open and interconnected pore structures are considered the most important characteristic of the TE scaffolds. ${ }^{35}$ Uniform multidirectional COL-based scaffolds were fabricated by unidirectional freeze casting of COL/HA and COL/hydroxyapatite suspensions. The scaffolds were joined by a lyophilization bonding process. With the arrangement of these compositional and architectural biomimetic cues, the scaffolds hold great capacity for zonal CTE. ${ }^{43}$ A novel class of hybrid scaffolds based on CHSN as a structural material and low portion of HA to mimic cartilage ECM were fabricated using FD. The results showed that incorporation of HA to the CHSN scaffolds enhanced the biological properties of the scaffolds, which had a superior porous structure network and exhibited higher cartilage ECM deposition. ${ }^{109}$ To fabricate porous hybrid constructs, CS was blended with SF to fabricate SF/CS scaffolds via FD. The scaffolds showed a pore size of $37-$
$212 \mu \mathrm{m}$, contact angle 46.2-50.38, biodegradation, and controlled swelling. Biocompatibility was confirmed by implantation of scaffolds subcutaneously in a mouse. The results indicated that incorporation of CS to the scaffolds promoted proliferation, cell attachment, and metabolic activity of hMSCs in vitro. ${ }^{130}$ Despite the great advantage of using the FD technique in fabrication of hybrid constructs in CTE, a small and nonhomogeneous pore size can be considered the main limitation of this method for several materials.

\section{Solvent casting and particulate leaching techniques}

In particulate leaching (PL) techniques, pore size and porosity of the scaffolds can be controlled by a selection of appropriate porogen materials. Using this method, numerous porous structures have been fabricated from varied synthetic and natural biomaterials for TE applications. ${ }^{79}$ Electrospinning combined with salt leaching (SL) has also been used to fabricate macroporous and nanofibrous HA scaffolds. HA and COL were electrospun into a nanofiber mesh by the deposition of salt particles during electrospinning and following crosslinking and SL. Cytocompatibility of the scaffold was evaluated by culturing bovine chondrocytes on the HA/COL scaffolds. The results demonstrated that cell proliferation was improved and COL content enhanced. ${ }^{122}$ Gas foaming/SL was used for the fabrication of PLGA/HA hybrid scaffolds. The PLGA scaffolds were fabricated by blending PLGA with varying amounts of amine-terminated PLGA-PEG diblock copolymers. Gene expression results, biochemical assays, and histological analysis showed that HA-modified scaffolds supported higher cartilage ECM formation, COL II gene expression, and morphological characteristics. ${ }^{174}$ Porous scaffolds based on poly(3hydroxybutyrate-co-3-hydroxyhexanoate) tubes were fabricated using a dipping method followed by SL. Culture of hMSCs on hybrid scaffolds showed early chondrogenic differentiation by expression of SOX9 in the presence of a proper induction medium. ${ }^{60}$ Nanocomposite scaffolds composed of PLGA/HA/fibrin/bioglass were prepared using solvent casting and PL (SC-PL) techniques. The scaffolds showed proper porosity percentage $(87.01 \pm 3 \%)$ with interconnected pore morphologies and pore size between 100 and $200 \mu \mathrm{m}$. The nanocomposite scaffold was cytocompatible, and the human adipose tissue-derived mesenchymal stem cells attached and proliferated on the scaffold. These scaffolds can be used for CTE applications. ${ }^{102}$ To overcome the possible disadvantages of PLGA, such as its hydrophobicity, limited support of nutrient exchange, and induction of inflammatory responses, micronized porcine cartilage (MPC) was added to the scaffolds to reduce the inflammatory effects and improve cell attachment and proliferation. PLGA and MPC/PLGA scaffolds were fabricated by the SC-PL technique. The results showed that incorporation of bioactive materials of MPC had constructive effects for enhancing PLGA scaffold biocompatibility. ${ }^{149}$

\section{Future Outlook}

About 132 articles published between 2000 and 2018, describing ECM-based hybrid and composite scaffolds used in CTE, were reviewed in the present study (Tables 1-4). A statistical analysis demonstrates which materials and methods are the most frequently used for ECM-based 
hybrid scaffold fabrication. To evaluate frequency of the different materials and methods, the number of published articles for each material or method was divided by total number of published articles during these years [frequency percentage $=$ (number of published articles for each materials or methods/total number of published articles) $\times 100$ ]. The results indicated that between cartilage ECM derivatives, the most frequently used materials were COL (40\%), HA (34\%), CS (14\%), and cECMa (12\%). According to the results, the most used synthetic materials to design hybrid and composite scaffolds in CTE are PLGA (18\%), MA (16\%), PCL (15\%), PEG (9\%), PVA (9\%), and PLA $(8 \%)$, and other polymeric materials consisting of poly-N(vinylcaprolactam), other polyesters, polyurethanes, and PGA (25\% totally). Among natural biomaterials, CHSN (41\%), SF (21\%), ALG (14\%), fibrin (11\%), and AGR $(5 \%)$, respectively, were the most frequently used in CTE. Finally, among scaffolding methods for fabrication of hybrid scaffolds at CTE applications, hydrogels (38\%), fibrous scaffolds (22\%), FD (15\%), 3D printing (10\%), SCPL (6\%), and other methods consisting of the microsphere, mesh-microsponge, fiber-hydrogel ( $9 \%$ totally) were more familiar, respectively. COL and HA have been mostly used in the fabrication of hybrid scaffolds in comparison with other ECM derivatives. These two polymers have been thoroughly investigated because of their biocompatibility, biomimetic properties, and abundance. As shown in the beginning, synthetic polymers, PLGA, PCL, and MA, were more frequently used hybrid scaffolds than PVA, PLA, and PEG polymers. PLGA and PCL are biodegradable, biocompatible, and their rate of biodegradation can be controlled by the degree of hybridization with other synthetic and natural biomaterials. Results demonstrated that CHSN has been used the most frequently as a natural biomaterial in the fabrication of hybrid scaffolds. CHSN biostability is due to its large number of reactive amino groups that play a useful role as sites for specific crosslinking. CHSN is miscible at the molecular level and it exhibits hydrogen bonding or electrostatic interactions that contribute to mechanical stability. Furthermore, adding CHSN to ECM derivatives increases the number of crosslinking sites. When crosslinked, these hybrid scaffolds prevent access to hydrolytic enzymes to the sensitive cleavage sites of ECM derivatives. Biostability on the one hand and degradation rates on the other hand can be controlled by the extent and type of crosslinking. Finally, among the fabrication methods, hydrogels and fibrous approaches were the most common in CTE application.

As the results show, collagens and HA were used most frequently in the fabrication of hybrid scaffolds. However, according to articles published in recent years, the use of ECM analogs in the preparation of hybrid scaffolds for CTE applications has been expanding due to the potential to induce SC differentiation.

Among natural biomaterials, $\mathrm{CHSN}$ has been widely used due to its miscibility with ECM derivatives, and the presence of functional groups for crosslinking with ECM derivatives, all important features for cartilage tissue repair. With regard to fabrication, hydrogels and fibers are used most frequently in hybrid scaffold fabrication due to their similarity to natural cartilage structure. There is also a growing trend with the use of injectable hydrogels and biofabrication methods for CTE.

\section{Conclusions}

In hybrid scaffold fabrication, ECM-derived biomolecules are combined with natural or synthetic biomaterials. Because of their specific biophysical and biochemical properties, hybrid scaffolds provide superior interactions with cells and better control of cell adhesion, spreading, proliferation, and differentiation. ECM-derived hybrid scaffolds are promising materials for cartilage and other TE needs. Hybrid scaffolds consisting of cell-derived ECM and synthetic materials have superior mechanical properties compared with acellular tissues and pure ECM scaffolds. Based on the reviewed publications, it is possible to conclude that COL and HA are the most frequently used in hybrid scaffolds for CTE, and that from the perspective of fabrication or process or material format, fibrous and hydrogel scaffolds are the most popular.

\section{Acknowledgment}

The authors thank Prof. Bernhard Erni, University of Bern, for helpful discussions and assistance in preparing the present article.

\section{Disclosure Statement}

No competing financial interests exist.

\section{References}

1. Tuan, R.S., and Chen, F.H. Cartilage. In: Battler, A., and Leor, J., eds. Stem Cell and Gene-Based Therapy. London: Springer, 2006, pp. 179-193.

2. Mankin, H.J., Mow, V.C., Buckwalter, J.A., Iannotti, J.P., and Ratcliffe, A. Articular cartilage structure, composition, and function. Orthop Basic Sci 2, 443, 2000.

3. Mow, V.C., Ratcliffe, A., and Poole, A.R. Cartilage and diarthrodial joints as paradigms for hierarchical materials and structures. Biomaterials 13, 67, 1992.

4. Eggli, P.S., Hunzinker, E.B., and Schenk, R.K. Quantitation of structural features characterizing weight- and lessweight-bearing regions in articular cartilage: a stereological analysis of medical femoral condyles in young adult rabbits. Anat Rec 222, 217, 1988.

5. Wong, M., Wuethrich, P., Eggli, P., and Hunziker, E. Zone-specific cell biosynthetic activity in mature bovine articular cartilage: a new method using confocal microscopic stereology and quantitative autoradiography. $\underline{\mathbf{J}}$ Orthop Res 14, 424, 1996.

6. Wu, J.Z., and Herzog, W. Elastic anisotropy of articular cartilage is associated with the microstructures of collagen fibers and chondrocytes. J Biomech 35, 931, 2002.

7. Scadden, D.T. The stem-cell niche as an entity of action. Nature 441, 1075, 2006.

8. Weissman, I.L. Translating stem and progenitor cell biology to the clinic: barriers and opportunities. Science 287, 1442, 2000.

9. Mousavi, S.J., and Hamdy Doweidar, M. Role of mechanical cues in cell differentiation and proliferation: A 3D numerical model. PLoS One 10, e0124529, 2015.

10. Engler, A.J., Sen, S., Sweeney, H.L., and Discher, D.E. Matrix elasticity directs stem cell lineage specification. Cell 126, 677, 2006.

11. Becerra, J., Santos-Ruiz, L., Andrades, J.A., and MaríBeffa, M. The stem cell niche should be a key issue for 
cell therapy in regenerative medicine. Stem Cell Rev 7, 248, 2011.

12. Geiger, B., Spatz, J.P., and Bershadsky, A.D. Environmental sensing through focal adhesions. Nat Rev Mol Cell Biol 10, 21, 2009.

13. Holle, A.W., and Engler, A.J. More than a feeling: discovering, understanding, and influencing mechanosensing pathways. Curr Opin Biotechnol 22, 648, 2011.

14. Sekiya, I., Larson, B.L., Smith, J.R., Pochampally, R., Cui, J.G., and Prockop, D.J. Expansion of human adult stem cells from bone marrow stroma: conditions that maximize the yields of early progenitors and evaluate their quality. Stem Cells 20, 530, 2002.

15. Bertolo, A., Mehr, M., Aebli, N., Baur, M., Ferguson, S.J., and Stoyanov, J.V. Influence of different commercial scaffolds on the in vitro differentiation of human mesenchymal stem cells to nucleus pulposus-like cells. Eur Spine J 21, S826, 2012.

16. Farrell, E., O’Brien, F.J., Doyle, P., et al. A collagenglycosaminoglycan scaffold supports adult rat mesenchymal stem cell differentiation along osteogenic and chondrogenic routes. Tissue Eng 12, 459, 2006.

17. Charlton, D.C., Peterson, M.G., Spiller, K., Lowman, A., Torzilli, P.A., and Maher, S.A. Semi-degradable scaffold for articular cartilage replacement. Tissue Eng Part A 14, 207, 2008.

18. Kang, S.W., Seo, S.W., Choi, C.Y., and Kim, B.S. Porous poly(lactic-co-glycolic acid) microsphere as cell culture substrate and cell transplantation vehicle for adipose tissue engineering. Tissue Eng Part C Methods 14, 25, 2008.

19. Young, R.C., Schumann, R., and Zhang, P. Threedimensional culture of human uterine smooth muscle myocytes on a resorbable scaffolding. Tissue Eng 9, 451, 2003.

20. Heo, S.-J., Kim, S.-E., Wei, J., et al. In vitro and animal study of novel nano-hydroxyapatite/poly( $\varepsilon$-caprolactone) composite scaffolds fabricated by layer manufacturing process. Tissue Eng Part A 15, 977, 2009.

21. He, X., Lu, H., Kawazoe, N., Tateishi, T., and Chen, G. A novel cylinder-type poly(L-lactic acid)-collagen hybrid sponge for cartilage tissue engineering. Tissue Eng Part C Methods 16, 329, 2010.

22. Varghese, S., and Elisseeff, J.H. Hydrogels for musculoskeletal tissue engineering. In: Werner, C., ed. Polymers for Regenerative Medicine. Berlin: Springer, 2006, pp. 95-144.

23. Hwang, N.S., Varghese, S., Li, H., and Elisseeff, J. Regulation of osteogenic and chondrogenic differentiation of mesenchymal stem cells in PEG-ECM hydrogels. Cell Tissue Res 344, 499, 2011.

24. Van der Rest, M., and Garrone, R. Collagen family of proteins. FASEB J 5, 2814, 1991.

25. Fratzl, P. Collagen: Structure and Mechanics. Boston, MA: Springer Science \& Business Media, 2008, pp. 1-13.

26. Glowacki, J., and Mizuno, S. Collagen scaffolds for tissue engineering. Biopolymers 89, 338, 2008.

27. Doulabi, A.H., Mequanint, K., and Mohammadi, H. Blends and nanocomposite biomaterials for articular cartilage tissue engineering. Materials 7, 5327, 2014.

28. Yang, X., Guo, L., Fan, Y., and Zhang, X. Preparation and characterization of macromolecule cross-linked collagen hydrogels for chondrocyte delivery. Int J Biol Macromol 61, 487, 2013.
29. Yan, L.P., Wang, Y.J., Ren, L., et al. Genipin-cross-linked collagen/chitosan biomimetic scaffolds for articular cartilage tissue engineering applications. J Biomed Mater Res Part A 95, 465, 2010.

30. Sionkowska, A., Wisniewski, M., Skopinska, J., Kennedy, C.J., and Wess, T.J. Molecular interactions in collagen and chitosan blends. Biomaterials 25, 795, 2004.

31. Liu, X., Won, Y., and Ma, P.X. Porogen-induced surface modification of nano-fibrous poly(L-lactic acid) scaffolds for tissue engineering. Biomaterials 27, 3980, 2006.

32. Zhu, W., Cui, H., Boualam, B., et al. 3D bioprinting mesenchymal stem cell-laden construct with core-shell nanospheres for cartilage tissue engineering. Nanotechnology 29, 185101, 2018.

33. Cheng, Z., Landish, B., Chi, Z., et al. 3D printing hydrogel with graphene oxide is functional in cartilage protection by influencing the signal pathway of Rank/ Rankl/OPG. Mater Sci Eng C 82, 244, 2018.

34. He, Y., Liu, W., Guan, L., et al. A 3D-printed PLCL scaffold coated with collagen type I and its biocompatibility. BioMed Res Int 2018, 5147156, 2018.

35. Kaczmarek, B., Sionkowska, A., and Stojkovska, J. Characterization of scaffolds based on chitosan and collagen with glycosaminoglycans and sodium alginate addition. Polym Test 68, 229, 2018.

36. Yang, X., Lu, Z., Wu, H., Li, W., Zheng, L., and Zhao, J. Collagen-alginate as bioink for three-dimensional (3D) cell printing based cartilage tissue engineering. Mater Sci Eng C 83, 195, 2018.

37. Gao, Y., Kong, W., Li, B., et al. Fabrication and characterization of collagen-based injectable and selfcrosslinkable hydrogels for cell encapsulation. Colloids Surf B Biointerfaces 167, 448, 2018.

38. Chen, J.X., Yuan, J., Wu, Y.L., et al. Fabrication of tough poly(ethylene glycol)/collagen double network hydrogels for tissue engineering. J Biomed Mater Res A 106, 192, 2018.

39. Mekhileri, N.V., Lim, K.S., Brown, G.C.J., et al. Automated 3D bioassembly of micro-tissues for biofabrication of hybrid tissue engineered constructs. Biofabrication 10, 024103, 2018.

40. Bas, O., Lucarotti, S., Angella, D.D., et al. Rational design and fabrication of multiphasic soft network composites for tissue engineering articular cartilage: a numerical modelbased approach. Chem Eng J 340, 15, 2018.

41. Saghebasl, S., Davaran, S., Rahbarghazi, R., Montaseri, A., Salehi, R., and Ramazani, A. Synthesis and in vitro evaluation of thermosensitive hydrogel scaffolds based on (PNIPAAm-PCL-PEG-PCL-PNIPAAm)/Gelatin and (PCL-PEG-PCL)/Gelatin for use in cartilage tissue engineering. J Biomater Sci Polym Ed 29, 1185, 2018.

42. Song, J.E., Tripathy, N., Cha, S.R., et al. Threedimensional duck's feet collagen/PLGA scaffold for chondrification: role of pore size and porosity. $\underline{\mathrm{J} \text { Biomater }}$ Sci Polym Ed 29, 932, 2018.

43. Clearfield, D., Nguyen, A., and Wei, M. Biomimetic multidirectional scaffolds for zonal osteochondral tissue engineering via a lyophilization bonding approach. $\underline{\mathbf{J}}$ Biomed Mater Res A 106, 948, 2018.

44. Huang, G.P., Molina, A., Tran, N., Collins, G., and Arinzeh, T.L. Investigating cellulose derived glycosaminoglycan mimetic scaffolds for cartilage tissue engineering applications. J Tissue Eng Regen Med 12, e592, 2018. 
45. D'Amora, U., D'Este, M., Eglin, D., et al. Collagen density gradient on three-dimensional printed poly( $\varepsilon$-caprolactone) scaffolds for interface tissue engineering. J Tissue Eng Regen Med 12, 321, 2018.

46. Jeon, O., Shin, J.-Y., Marks, R., et al. Highly elastic and tough interpenetrating polymer network-structured hybrid hydrogels for cyclic mechanical loading-enhanced tissue engineering. Chem Mater 29, 8425, 2017.

47. Agheb, M., Dinari, M., Rafienia, M., and Salehi, H. Novel electrospun nanofibers of modified gelatin-tyrosine in cartilage tissue engineering. Mater Sci Eng C 71, $240,2017$.

48. Kalaithong, W., Molloy, R., Theerathanagorn, T., and Janvikul, W. Novel poly(L-lactide-co-caprolactone)/gelatin porous scaffolds for use in articular cartilage tissue engineering: comparison of electrospinning and wet spinning processing methods. Polym Eng Sci 57, 875, 2017.

49. Shi, W., Sun, M., Hu, X., et al. Structurally and functionally optimized silk-fibroin-gelatin scaffold using 3D printing to repair cartilage injury in vitro and in vivo. Adv Mater 29, $1701089,2017$.

50. Almeida, H.V., Sathy, B.N., Dudurych, I., Buckley, C.T., O'Brien, F.J., and Kelly, D.J. Anisotropic shape-memory alginate scaffolds functionalized with either type I or type II collagen for cartilage tissue engineering. Tissue Eng Part A 23, 55, 2017.

51. Levato, R., Webb, W.R., Otto, I.A., et al. The bio in the ink: cartilage regeneration with bioprintable hydrogels and articular cartilage-derived progenitor cells. Acta Biomater 61, 41, 2017.

52. Wang, J., Yang, Q., Cheng, N., et al. Collagen/silk fibroin composite scaffold incorporated with PLGA microsphere for cartilage repair. Mater Sci Eng C 61, 705, 2016.

53. Naseri, N., Poirier, J.-M., Girandon, L., Fröhlich, M., Oksman, K., and Mathew, A.P. 3-Dimensional porous nanocomposite scaffolds based on cellulose nanofibers for cartilage tissue engineering: tailoring of porosity and mechanical performance. Rsc Adv 6, 5999, 2016.

54. Studer, D., Cavalli, E., Formica, F.A., et al. Human chondroprogenitors in alginate-collagen hybrid scaffolds produce stable cartilage in vivo. $\mathbf{J}$ Tissue Eng Regen Med 11, 3014, 2017.

55. Bas, O., De-Juan-Pardo, E.M., Chhaya, M.P., et al. Enhancing structural integrity of hydrogels by using highly organised melt electrospun fibre constructs. Eur Polym J 72, 451, 2015.

56. He, X., Feng, B., Huang, C., et al. Electrospun gelatin/ polycaprolactone nanofibrous membranes combined with a coculture of bone marrow stromal cells and chondrocytes for cartilage engineering. Int $\mathrm{J}$ Nanomater 10, 2089, 2015.

57. Liu, S., Wu, J., Liu, X., et al. Osteochondral regeneration using an oriented nanofiber yarn-collagen type I/hyaluronate hybrid/TCP biphasic scaffold. J Biomed Mater Res A 103, 581, 2015 .

58. Yin, F., Cai, J., Zen, W., et al. Cartilage regeneration of adipose-derived stem cells in the TGF- $\beta 1$-immobilized PLGA-gelatin scaffold. Stem Cell Rev 11, 453, 2015.

59. Haaparanta, A.M., Järvinen, E., Cengiz, I.F., et al. Preparation and characterization of collagen/PLA, chitosan/ PLA, and collagen/chitosan/PLA hybrid scaffolds for cartilage tissue engineering. J Mater Sci Mater Med 25, 1129, 2014.

60. Lomas, A.J., Webb, W.R., Han, J., et al. Poly(3hydroxybutyrate-co-3-hydroxyhexanoate)/collagen hybrid scaffolds for tissue engineering applications. Tissue Eng Part C Methods 19, 577, 2013.

61. Dai, W., Yao, Z., Dong, J., Kawazoe, N., Zhang, C., and Chen, G. Cartilage tissue engineering with controllable shape using a poly(lactic-co-glycolic acid)/collagen hybrid scaffold. J Bioact Compat Polym 28, 247, 2013.

62. Xu, T., Binder, K.W., Albanna, M.Z., et al. Hybrid printing of mechanically and biologically improved constructs for cartilage tissue engineering applications. Biofabrication 5, 015001, 2013.

63. Kim, H.J., Kim, K.K., Park, I.K., Choi, B.S., Kim, J.H., and Kim, M.S. Hybrid scaffolds composed of hyaluronic acid and collagen for cartilage regeneration. Tissue Eng Regen Med 9, 57, 2012.

64. Bhat, S., Lidgren, L., Kumar, A. In vitro neo-cartilage formation on a three-dimensional composite polymeric cryogel matrix. Macromol Biosci 13, 827, 2013.

65. Chen, W.C., Yao, C.L., Wei, Y.H., and Chu, I.M. Evaluating osteochondral defect repair potential of autologous rabbit bone marrow cells on type II collagen scaffold. Cytotechnology 63, 13, 2011.

66. Abedi, G., Sotoudeh, A., Soleymani, M., Shafiee, A., Mortazavi, P., and Aflatoonian, M.R. A collagenpoly(vinyl alcohol) nanofiber scaffold for cartilage repair. J Biomater Sci Polym Ed 22, 2445, 2011.

67. Bi, L., Cao, Z., Hu, Y., et al. Effects of different crosslinking conditions on the properties of genipin-crosslinked chitosan/collagen scaffolds for cartilage tissue engineering. J Mater Sci Mater Med 22, 51, 2011.

68. Qu, D., Li, J., Li, Y., et al. Ectopic osteochondral formation of biomimetic porous PVA-n-HA/PA6 bilayered scaffold and BMSCs construct in rabbit. J Biomed Mater Res B Appl Biomater 96B, 9, 2011.

69. Zhang, L., Li, K., Xiao, W., et al. Preparation of collagenchondroitin sulfate-hyaluronic acid hybrid hydrogel scaffolds and cell compatibility in vitro. Carbohydr Polym 84, 118, 2011.

70. Ho, S.T., Cool, S.M., Hui, J.H., and Hutmacher, D.W. The influence of fibrin based hydrogels on the chondrogenic differentiation of human bone marrow stromal cells. Biomaterials 31, 38, 2010.

71. Dai, W., Kawazoe, N., Lin, X., Dong, J., and Chen, G. The influence of structural design of PLGA/collagen hybrid scaffolds in cartilage tissue engineering. Biomaterials 31, 2141, 2010.

72. Guo, X., Park, H., Young, S., et al. Repair of osteochondral defects with biodegradable hydrogel composites encapsulating marrow mesenchymal stem cells in a rabbit model. Acta Biomater 6, 39, 2010.

73. Kathuria, N., Tripathi, A., Kar, K.K., and Kumar, A. Synthesis and characterization of elastic and macroporous chitosan-gelatin cryogels for tissue engineering. Acta Biomater 5, 406, 2009.

74. Ko, C.S., Huang, J.P., Huang, C.W., and Chu, I.M. Type II collagen-chondroitin sulfate-hyaluronan scaffold crosslinked by genipin for cartilage tissue engineering. J Biosci Bioeng 107, 177, 2009.

75. Buttafoco, L., Kolkman, N.G., Engbers-Buijtenhuijs, P., et al. Electrospinning of collagen and elastin for tissue engineering applications. Biomaterials 27, 724, 2006.

76. Tan, W., Krishnaraj, R., and Desai, T.A. Evaluation of nanostructured composite collagen-chitosan matrices for tissue engineering. Tissue Eng 7, 203, 2001. 
77. Hillel, A., Shah, P., and Elisseeff, J.H. Hydrogels in cell encapsulation and tissue engineering. In: Biodmedical Polymers. Woodhead Publishing, 2007. pp. 57-82.

78. Kim, D.-D., Kim, D.-H., and Son, Y.-J. Threedimensional porous scaffold of hyaluronic acid for cartilage tissue engineering. In: Zilberman, M., ed. Active Implants and Scaffolds for Tissue Regeneration (Studies in Mechanobiology, Tissue Engineering and Biomaterials). Berlin: Springer, 2010, pp. 329-349.

79. Collins, M.N., and Birkinshaw, C. Hyaluronic acid based scaffolds for tissue engineering - a review. Carbohydr Polym 92, 1262, 2013.

80. Muzzarelli, R.A., Greco, F., Busilacchi, A., Sollazzo, V., and Gigante, A. Chitosan, hyaluronan and chondroitin sulfate in tissue engineering for cartilage regeneration: a review. Carbohydr Polym 89, 723, 2012.

81. Widner, B., Behr, R., Von Dollen, S., et al. Hyaluronic acid production in Bacillus subtilis. Appl Environ Microbiol 71, 3747, 2005.

82. Mattheolabakis, G., Milane, L., Singh, A., and Amiji, M.M. Hyaluronic acid targeting of CD44 for cancer therapy: from receptor biology to nanomedicine. J Drug Target 23, 605, 2015.

83. Teong, B., Wu, S.C., Chang, C.M., et al. The stiffness of a crosslinked hyaluronan hydrogel affects its chondro-induction activity on hADSCs. J Biomed Mater Res B Appl Biomater 106, 808, 2018.

84. Seidlits, S.K., Drinnan, C.T., Petersen, R.R., Shear, J.B., Suggs, L.J., and Schmidt, C.E. Fibronectin-hyaluronic acid composite hydrogels for three-dimensional endothelial cell culture. Acta Biomater 7, 2401, 2011.

85. Jung, A., Makkar, P., Amirian, J., and Lee, B.T. A novel hybrid multichannel biphasic calcium phosphate granulebased composite scaffold for cartilage tissue regeneration. J Biomater Appl 32, 775, 2018.

86. Hsieh, Y.-H., Shen, B.-Y., Wang, Y.-H., Lin, B., Lee, H.M., and Hsieh, M.-F. Healing of osteochondral defects implanted with biomimetic scaffolds of poly(e-caprolactone)/hydroxyapatite and glycidyl-methacrylatemodified hyaluronic acid in a minipig. Int J Mol Sci 19, 1125, 2018.

87. Zhu, C., Yang, R., Hua, X., et al. Highly stretchable HA/ SA hydrogels for tissue engineering. J Biomater Sci Polym Ed 29, 543, 2018.

88. Karabiyik Acar, O., Kayitmazer, A.B., and Torun Kose, G. Hyaluronic acid/chitosan coacervate-based scaffolds. Biomacromolecules 19, 1198, 2018.

89. Schiavi, J., Reppel, L., Charif, N., et al. Mechanical stimulations on human bone marrow mesenchymal stem cells enhance cells differentiation in a three-dimensional layered scaffold. J Tissue Eng Regen Med 12, 360, 2018.

90. Han, S.-S., Yoon, H.Y., Yhee, J.Y., et al. In situ crosslinkable hyaluronic acid hydrogels using copper free click chemistry for cartilage tissue engineering. Polym Chem 9, 20, 2018.

91. Wang, H., Zhu, D., Paul, A., et al. Covalently adaptable elastin-like protein-hyaluronic acid (ELP-HA) hybrid hydrogels with secondary thermoresponsive crosslinking for injectable stem cell delivery. Adv Funct Mater 27, 2017, 1605609.

92. Zhu, D., Wang, H., Trinh, P., Heilshorn, S.C., and Yang, F. Elastin-like protein-hyaluronic acid (ELP-HA) hydrogels with decoupled mechanical and biochemical cues for cartilage regeneration. Biomaterials 127, 132, 2017.
93. Shie, M.Y., Chang, W.C., Wei, L.J., et al. 3D printing of cytocompatible water-based light-cured polyurethane with hyaluronic acid for cartilage tissue engineering applications. Materials 10, 136, 2017.

94. Raia, N.R., Partlow, B.P., McGill, M., Kimmerling, E.P., Ghezzi, C.E., and Kaplan, D.L. Enzymatically crosslinked silk-hyaluronic acid hydrogels. Biomaterials 131, 58, 2017.

95. Lin, X., Wang, W., Zhang, W., et al. Hyaluronic acid coating enhances biocompatibility of nonwoven PGA scaffold and cartilage formation. Tissue Eng Part C Methods 23, 86, 2017.

96. Chen, F., Ni, Y., Liu, B., et al. Self-crosslinking and injectable hyaluronic acid/RGD-functionalized pectin hydrogel for cartilage tissue engineering. Carbohydr Polym 166, 31, 2017.

97. Kim, D.Y., Park, H., Kim, S.W., Lee, J.W., and Lee, K.Y. Injectable hydrogels prepared from partially oxidized hyaluronate and glycol chitosan for chondrocyte encapsulation. Carbohydr Polym 157, 1281, 2017.

98. Park, H., Lee, H.J., An, H., and Lee, K.Y. Alginate hydrogels modified with low molecular weight hyaluronate for cartilage regeneration. Carbohydr Polym 162, 100, 2017.

99. Lynch, B., Crawford, K., Baruti, O., et al. The effect of hypoxia on thermosensitive poly( $\mathrm{N}$-vinylcaprolactam) hydrogels with tunable mechanical integrity for cartilage tissue engineering. J Biomed Mater Res 105, 1863, 2017.

100. Dai, Y., Gao, Z., Ma, L., Wang, D., and Gao, C. Cell-free HA-MA/PLGA scaffolds with radially oriented pores for in situ inductive regeneration of full thickness cartilage defects. Macromol Biosci 16, 1632, 2016.

101. Shim, J.H., Jang, K.M., Hahn, S.K., et al. Threedimensional bioprinting of multilayered constructs containing human mesenchymal stromal cells for osteochondral tissue regeneration in the rabbit knee joint. Biofabrication 8, 014102, 2016.

102. Tavakoli, E., Mehdikhani-Nahrkhalaji, M., HashemiBeni, B., Zargar-Kharazi, A., and Kharaziha, M. Preparation, characterization and mechanical assessment of poly(lactide-co-glycolide)/hyaluronic acid/fibrin/bioactive glass nano-composite scaffolds for cartilage tissue engineering applications. Procedia Mater Sci 11, 124, 2015.

103. Snyder, T.N., Madhavan, K., Intrator, M., Dregalla, R.C., and Park, D. A fibrin/hyaluronic acid hydrogel for the delivery of mesenchymal stem cells and potential for articular cartilage repair. J Biol Eng 8, 10, 2014.

104. Mintz, B.R., and Cooper, J.A. Hybrid hyaluronic acid hydrogel/poly( $\varepsilon$-caprolactone) scaffold provides mechanically favorable platform for cartilage tissue engineering studies. J Biomed Mater Res 102, 2918, 2014.

105. Levett, P.A., Melchels, F.P., Schrobback, K., Hutmacher, D.W., Malda, J., and Klein, T.J. A biomimetic extracellular matrix for cartilage tissue engineering centered on photocurable gelatin, hyaluronic acid and chondroitin sulfate. Acta Biomater 10, 214, 2014.

106. Wang, T., Lai, J.H., Han, L.H., Tong, X., and Yang, F. Chondrogenic differentiation of adipose-derived stromal cells in combinatorial hydrogels containing cartilage matrix proteins with decoupled mechanical stiffness. Tissue Eng Part A 20, 2131, 2014.

107. Schuurman, W., Levett, P.A., Pot, M.W., et al. Gelatinmethacrylamide hydrogels as potential biomaterials for 
fabrication of tissue-engineered cartilage constructs. Macromol Biosci 13, 551, 2013.

108. Murphy, C.M., Matsiko, A., Haugh, M.G., Gleeson, J.P., and O'Brien, F.J. Mesenchymal stem cell fate is regulated by the composition and mechanical properties of collagen-glycosaminoglycan scaffolds. J Mech Behav Biomed Mater 11, 53, 2012.

109. Correia, C.R., Moreira-Teixeira, L.S., Moroni, L., et al. Chitosan scaffolds containing hyaluronic acid for cartilage tissue engineering. Tissue Eng Part C Methods 17, 717, 2011.

110. Coburn, J., Gibson, M., Bandalini, P.A., et al. Biomimetics of the extracellular matrix: an integrated threedimensional fiber-hydrogel composite for cartilage tissue engineering. Smart Struct Syst 7, 213, 2011.

111. Lee, J.S., and Lee, E.K. FGF-2-expanded costal chondrocytes regenerate hyaline cartilage in rabbit osteochondral defects. Tissue Eng Regen Med 8, 200, 2011.

112. Jin, R., Moreira Teixeira, L.S., Krouwels, A., et al. Synthesis and characterization of hyaluronic acidpoly(ethylene glycol) hydrogels via Michael addition: an injectable biomaterial for cartilage repair. Acta Biomater 6, 1968, 2010.

113. Jin, R., Teixeira, L.S., Dijkstra, P.J., Van Blitterswijk, C.A., Karperien, M., and Feijen, J. Enzymaticallycrosslinked injectable hydrogels based on biomimetic dextran-hyaluronic acid conjugates for cartilage tissue engineering. Biomaterials 31, 3103, 2010.

114. Fan, H., Tao, H., Wu, Y., Hu, Y., Yan, Y., and Luo, Z. TGF- $\beta 3$ immobilized PLGA-gelatin/chondroitin sulfate/ hyaluronic acid hybrid scaffold for cartilage regeneration. J Biomed Mater Res A 95, 982, 2010.

115. Im, G.I., Ahn, J.H., Kim, S.Y., Choi, B.S., and Lee, S.W. A hyaluronate-atelocollagen/beta-tricalcium phosphatehydroxyapatite biphasic scaffold for the repair of osteochondral defects: a porcine study. Tissue Eng Part A 16, 1189, 2010.

116. Tan, H., Chu, C.R., Payne, K.A., and Marra, K.G. Injectable in situ forming biodegradable chitosan-hyaluronic acid based hydrogels for cartilage tissue engineering. Biomaterials 30, 2499, 2009.

117. Tan, H., Wu, J., Lao, L., and Gao, C. Gelatin/chitosan/ hyaluronan scaffold integrated with PLGA microspheres for cartilage tissue engineering. Acta Biomater 5, 328, 2009.

118. Chen, J.-P., and Cheng, T.-H. Preparation and evaluation of thermo-reversible copolymer hydrogels containing chitosan and hyaluronic acid as injectable cell carriers. Polymer 50, 107, 2009.

119. Erggelet, C., Endres, M., Neumann, K., et al. Formation of cartilage repair tissue in articular cartilage defects pretreated with microfracture and covered with cell-free polymer-based implants. J Orthop Res 27, 1353, 2009.

120. Pereira, R.C., Scaranari, M., Castagnola, P., et al. Novel injectable gel (system) as a vehicle for human articular chondrocytes in cartilage tissue regeneration. J Tissue Eng Regen Med 3, 97, 2009.

121. Kasahara, Y., Iwasaki, N., Yamane, S., et al. Development of mature cartilage constructs using novel threedimensional porous scaffolds for enhanced repair of osteochondral defects. J Biomed Mater Res A 86, 127, 2008.

122. Kim, T.G., Chung, H.J., and Park, T.G. Macroporous and nanofibrous hyaluronic acid/collagen hybrid scaf- fold fabricated by concurrent electrospinning and deposition/leaching of salt particles. Acta Biomater 4, 1611, 2008.

123. Solchaga, L.A., Temenoff, J.S., Gao, J., Mikos, A.G., Caplan, A.I., and Goldberg, V.M. Repair of osteochondral defects with hyaluronan- and polyester-based scaffolds. Osteoarthritis Cartilage 13, 297, 2005.

124. Yamane, S., Iwasaki, N., Majima, T., et al. Feasibility of chitosan-based hyaluronic acid hybrid biomaterial for a novel scaffold in cartilage tissue engineering. Biomaterials 26, 611, 2005.

125. Athansou, N.A., Puddle, B., and Sallie, B. Highly sulphated glycosaminoglycans in articular cartilage and other tissues containing $\beta 2$ microglobulin dialysis amyloid deposits. Nephrol Dial Transplant 10, 1672, 1995.

126. Nanda, S., Sood, N., Reddy, B.V.K., and Markandeywar, T.S. Preparation and characterization of poly(vinyl alcohol)-chondroitin sulphate hydrogel as scaffolds for articular cartilage regeneration. Indian J Mater Sci 2013, $1,2013$.

127. Li, Q., Williams, C.G., Sun, D.D., Wang, J., Leong, K., and Elisseeff, J.H. Photocrosslinkable polysaccharides based on chondroitin sulfate. J Biomed Mater Res A 68, 28, 2004.

128. Ronca, F., Palmieri, L., Panicucci, P., and Ronca, G. Antiinflammatory activity of chondroitin sulfate. Osteoarthritis and cartilage / OARS, Osteoarthritis Research Society 6(Suppl. A), 14, 1998.

129. Yang, Y.L., Sun, C., Wilhelm, M.E., Fox, L.J., Zhu, J., and Kaufman, L.J. Influence of chondroitin sulfate and hyaluronic acid on structure, mechanical properties, and glioma invasion of collagen I gels. Biomaterials 32, 7932, 2011.

130. Agrawal, P., Pramanik, K., Vishwanath, V., Biswas, A., Bissoyi, A., and Patra, P.K. Enhanced chondrogenesis of mesenchymal stem cells over silk fibroin/chitosan-chondroitin sulfate three dimensional scaffold in dynamic culture condition. J Biomed Mater Res B Appl Biomater 106, 2576, 2018.

131. Bang, S., Jung, U.W., and Noh, I. Synthesis and biocompatibility characterizations of in situ chondroitin sulfate-gelatin hydrogel for tissue engineering. Tissue Eng Regen Med 15, 25, 2018.

132. Li, T., Song, X., Weng, C., et al. Self-crosslinking and injectable chondroitin sulfate/pullulan hydrogel for cartilage tissue engineering. Appl Mater Today 10, 173, 2018.

133. Piai, J.F., da Silva, M.A., Martins, A., et al. Chondroitin sulfate immobilization at the surface of electrospun nanofiber meshes for cartilage tissue regeneration approaches. Appl Surf Sci 403, 112, 2017.

134. Fan, M., Ma, Y., Tan, H., et al. Covalent and injectable chitosan-chondroitin sulfate hydrogels embedded with chitosan microspheres for drug delivery and tissue engineering. Mater Sci Eng C 71, 67, 2017.

135. Vishwanath, V., Pramanik, K., and Biswas, A. Development of a novel glucosamine/silk fibroin-chitosan blend porous scaffold for cartilage tissue engineering applications. Iran Polym J 26, 11, 2017.

136. Zhou, F., Zhang, X., Cai, D., et al. Silk fibroin-chondroitin sulfate scaffold with immuno-inhibition property for articular cartilage repair. Acta Biomater 63, 64, 2017.

137. Shahali, Z., Karbasi, S., Avadi, M.R., Semnani, D., Naghash Zargar, E., and HashemiBeni, B. Evaluation of 
structural, mechanical, and cellular behavior of electrospun poly-3-hydroxybutyrate scaffolds loaded with glucosamine sulfate to develop cartilage tissue engineering. Int J Polym Mater Polym Biomater 66, 589, 2017.

138. Chen, F., Yu, S., Liu, B., et al. An injectable enzymatically crosslinked carboxymethylated pullulan/chondroitin sulfate hydrogel for cartilage tissue engineering. Sci Rep 6, 20014, 2016.

139. Costantini, M., Idaszek, J., Szöke, K., et al. 3D bioprinting of BM-MSCs-loaded ECM biomimetic hydrogels for in vitro neocartilage formation. Biofabrication 8, 035002, 2016.

140. Liao, J., Qu, Y., Chu, B., Zhang, X., and Qian, Z. Biodegradable CSMA/PECA/graphene porous hybrid scaffold for cartilage tissue engineering. Sci Rep 5, 9879, 2015.

141. Sawatjui, N., Damrongrungruang, T., Leeanansaksiri, W., Jearanaikoon, P., Hongeng, S., and Limpaiboon, T. Silk fibroin/gelatin-chondroitin sulfate-hyaluronic acid effectively enhances in vitro chondrogenesis of bone marrow mesenchymal stem cells. Mater Sci Eng C 52, 90, 2015.

142. Naeimi, M., Fathi, M., Rafienia, M., and Bonakdar, S. Silk fibroin-chondroitin sulfate-alginate porous scaffolds: structural properties and in vitro studies. J Appl Polym Sci, 131, 41048, 2014.

143. Silva, J.M., Georgi, N., Costa, R., et al. Nanostructured 3D constructs based on chitosan and chondroitin sulphate multilayers for cartilage tissue engineering. PLoS One 8 , e55451, 2013.

144. Chen, Y.L., Lee, H.P., Chan, H.Y., Sung, L.Y., Chen, H.C., and Hu, Y.C. Composite chondroitin-6-sulfate/ dermatan sulfate/chitosan scaffolds for cartilage tissue engineering. Biomaterials 28, 2294, 2007.

145. Lee, C.-T., Kung, P.-H., and Lee, Y.-D. Preparation of poly(vinyl alcohol)-chondroitin sulfate hydrogel as matrices in tissue engineering. Carbohydr Polym 61, 348, 2005.

146. Benders, K.E., van Weeren, P.R., Badylak, S.F., Saris, D.B., Dhert, W.J., and Malda, J. Extracellular matrix scaffolds for cartilage and bone regeneration. Trends Biotechnol 31, 169, 2013.

147. Beck, E.C., Barragan, M., Tadros, M.H., Gehrke, S.H., and Detamore, M.S. Approaching the compressive modulus of articular cartilage with a decellularized cartilagebased hydrogel. Acta Biomater 38, 94, 2016.

148. Vinatier, C., Mrugala, D., Jorgensen, C., Guicheux, J., and Noël, D. Cartilage engineering: a crucial combination of cells, biomaterials and biofactors. Trends Biotechnol 27, 307, 2009.

149. Kim, S., Jang, J.E., Lee, J.H., and Khang, G. Composite scaffold of micronized porcine cartilage/poly(lactic-coglycolic acid) enhances anti-inflammatory effect. Mater Sci Eng C 88, 46, 2018.

150. Ghosh, P., Gruber, S.M.S., Lin, C.Y., and Whitlock, P.W. Microspheres containing decellularized cartilage induce chondrogenesis in vitro and remain functional after incorporation within a poly(caprolactone) filament useful for fabricating a 3D scaffold. Biofabrication 10, 025007, 2018.

151. Jung, C.S., Kim, B.K., Lee, J., Min, B.H., and Park, S.H. Development of printable natural cartilage matrix bioink for 3D printing of irregular tissue shape. Tissue Eng Regen Med 15, 155, 2018.

152. Ghassemi, T., Saghatolslami, N., Matin, M.M., Gheshlaghi, R., and Moradi, A. CNT-decellularized cartilage hybrids for tissue engineering applications. Biomed Mater 12, 065008, 2017.
153. Masaeli, E., Karamali, F., Loghmani, S., Eslaminejad, M.B., and Nasr-Esfahani, M.H. Bio-engineered electrospun nanofibrous membranes using cartilage extracellular matrix particles. J Mater Chem B 5, 765, 2017.

154. Rothrauff, B.B., Coluccino, L., Gottardi, R., et al. Efficacy of thermoresponsive, photocrosslinkable hydrogels derived from decellularized tendon and cartilage extracellular matrix for cartilage tissue engineering. J Tissue Eng Regen Med 12, e159, 2018.

155. Levingstone, T.J., Ramesh, A., Brady, R.T., et al. Cell-free multi-layered collagen-based scaffolds demonstrate layer specific regeneration of functional osteochondral tissue in caprine joints. Biomaterials 87, 69, 2016.

156. Nogami, M., Kimura, T., Seki, S., et al. A human amnionderived extracellular matrix-coated cell-free scaffold for cartilage repair: in vitro and in vivo studies. Tissue Eng Part A 22, 680, 2016.

157. Almeida, H.V., Eswaramoorthy, R., Cunniffe, G.M., Buckley, C.T., O'Brien, F.J., and Kelly, D.J. Fibrin hydrogels functionalized with cartilage extracellular matrix and incorporating freshly isolated stromal cells as an injectable for cartilage regeneration. Acta Biomater 36, 55, 2016.

158. Sutherland, A.J., and Detamore, M.S. Bioactive microsphere-based scaffolds containing decellularized cartilage. Macromol Biosci 15, 979, 2015.

159. Garrigues, N.W., Little, D., Sanchez-Adams, J., Ruch, D.S., and Guilak, F. Electrospun cartilage-derived matrix scaffolds for cartilage tissue engineering. J Biomed Mater Res A 102, 3998, 2014.

160. Levorson, E.J., Hu, O., Mountziaris, P.M., Kasper, F.K., and Mikos, A.G. Cell-derived polymer/extracellular matrix composite scaffolds for cartilage regeneration, Part 2: construct devitalization and determination of chondroinductive capacity. Tissue Eng Part C Methods 20, 358, 2014.

161. Liao, J., Guo, X., Grande-Allen, K.J., Kasper, F.K., and Mikos, A.G. Bioactive polymer/extracellular matrix scaffolds fabricated with a flow perfusion bioreactor for cartilage tissue engineering. Biomaterials 31, 8911, 2010.

162. Wang, Z.H., He, X.J., Yang, Z.Q., and Tu, J.B. Cartilage tissue engineering with demineralized bone matrix gelatin and fibrin glue hybrid scaffold: an in vitro study. Artif Organs 34, 161, 2010.

163. Ho, S.T.B., Ekaputra, A.K., Hui, J.H., and Hutmacher, D.W. An electrospun polycaprolactone-collagen membrane for the resurfacing of cartilage defects. Polym Int 59, 808, 2010.

164. Yamane, S., Iwasaki, N., Kasahara, Y., et al. Effect of pore size on in vitro cartilage formation using chitosanbased hyaluronic acid hybrid polymer fibers. Mater Res A 81, 586, 2007.

165. Coburn, J.M., Gibson, M., Monagle, S., Patterson, Z., and Elisseeff, J.H. Bioinspired nanofibers support chondrogenesis for articular cartilage repair. Proc Natl Acad Sci U S A 109, 10012, 2012.

166. Bhat, S., Tripathi, A., and Kumar, A. Supermacroprous chitosan-agarose-gelatin cryogels: in vitro characterization and in vivo assessment for cartilage tissue engineering. J R Soc Interface 8, 540, 2011.

167. Nafea, E.H., Poole-Warren, L.A., and Martens, P.J. Bioactivity of permselective PVA hydrogels with 
mixed ECM analogues. J Biomed Mater Res A 103, 3727, 2015.

168. Chua, C.K., and Leong, K.F. Rapid Prototyping: Principles and Applications. Singapore: World Scientific, 2003.

169. Markovic, M., Van Hoorick, J., Hölzl, K., et al. Hybrid tissue engineering scaffolds by combination of threedimensional printing and cell photoencapsulation. $\mathrm{J} \mathrm{Na}-$ notechnol Eng Med 6, 0210011, 2015,

170. Hofmann, S., and Garcia-Fuentes, M. Bioactive scaffolds for the controlled formation of complex skeletal tissues. In: Regenerative Medicine and Tissue Engineering-Cells and Biomaterials. IntechOpen, 2011, pp. 393-432.

171. Mironov, V., Visconti, R.P., Kasyanov, V., Forgacs, G., Drake, C.J., and Markwald, R.R. Organ printing: tissue spheroids as building blocks. Biomaterials 30, 2164, 2009.

172. Visser, J., Melchels, F.P., Jeon, J.E., et al. Reinforcement of hydrogels using three-dimensionally printed microfibres. Nat commun 6, 6933, 2015.

173. Chen, S., Zhang, Q., Nakamoto, T., Kawazoe, N., and Chen, G. Gelatin scaffolds with controlled pore structure and mechanical property for cartilage tissue engineering. Tissue Eng Part C Methods 22, 189, 2016.

174. Yoo, H.S., Lee, E.A., Yoon, J.J., and Park, T.G. Hyaluronic acid modified biodegradable scaffolds for cartilage tissue engineering. Biomaterials 26, 1925, 2005.
Address correspondence to: Mohammad T. Joghataei, PhD Department of Tissue Engineering and Regenerative Medicine

Faculty of Advanced Technologies in Medicine Iran University of Medical Sciences (IUMS)

Tehran 354-14665

Iran

E-mail: mt.joghataei@yahoo.com

Lorenzo Moroni, PhD

MERLN Institute for Technology Inspired

Regenerative Medicine

Complex Tissue Regeneration

Maastricht University

Maastricht 6229ER

The Netherlands

E-mail: 1.moroni@maastrichtuniversity.nl

Received: September 4, 2018

Accepted: January 1, 2019

Online Publication Date: June 17, 2019 


\section{This article has been cited by:}

1. Georgia Papaparaskeva, Maria Louca, Chrysovalantis Voutouri, Eugenia Tanasă, Triantafyllos Stylianopoulos, Theodora KrasiaChristoforou. 2020. Amalgamated fiber/hydrogel composites based on semi-interpenetrating polymer networks and electrospun nanocomposite fibrous mats. European Polymer Journal 140, 110041. [Crossref]

2. Flavia Pedrini, Moema Hausen, Rodrigo Gomes, Eliana Duek. 2020. Enhancement of cartilage extracellular matrix synthesis in Poly(PCL-TMC)urethane scaffolds: a study of oriented dynamic flow in bioreactor. Biotechnology Letters 5. . [Crossref]

3. Paul D. Dalton, Tim B. F. Woodfield, Vladimir Mironov, Jürgen Groll. 2020. Advances in Hybrid Fabrication toward Hierarchical Tissue Constructs. Advanced Science 7:11, 1902953. [Crossref]

4. Mohammad Amin Salati, Javad Khazai, Amir Mohammad Tahmuri, Ali Samadi, Ali Taghizadeh, Mohsen Taghizadeh, Payam Zarrintaj, Josh D. Ramsey, Sajjad Habibzadeh, Farzad Seidi, Mohammad Reza Saeb, Masoud Mozafari. 2020. Agarose-Based Biomaterials: Opportunities and Challenges in Cartilage Tissue Engineering. Polymers 12:5, 1150. [Crossref]

5. Sadaf Saeedi Garakani, Mehdi Khanmohammadi, Zhaleh Atoufi, Seyed Kamran Kamrava, Mohsen Setayeshmehr, Rafieh Alizadeh, Faezeh Faghihi, Zohreh Bagher, Seyed Mohammad Davachi, Alireza Abbaspourrad. 2020. Fabrication of chitosan/agarose scaffolds containing extracellular matrix for tissue engineering applications. International Journal of Biological Macromolecules 143, 533-545. [Crossref]

6. Anying Wang, Naixia Hu, Yefeng Zhang, Yuanzhen Chen, Changhui Su, Yao Lv, Yong Shen. 2019. MEG3 promotes proliferation and inhibits apoptosis in osteoarthritis chondrocytes by miR-361-5p/FOXO1 axis. BMC Medical Genomics 12:1. . [Crossref]

7. Zhaleh Atoufi, Seyed Kamran Kamrava, Seyed Mohammad Davachi, Majid Hassanabadi, Sadaf Saeedi Garakani, Rafieh Alizadeh, Mohammad Farhadi, Shima Tavakol, Zohreh Bagher, Ghodratollah Hashemi Motlagh. 2019. Injectable PNIPAM/Hyaluronic acid hydrogels containing multipurpose modified particles for cartilage tissue engineering: Synthesis, characterization, drug release and cell culture study. International Journal of Biological Macromolecules 139, 1168-1181. [Crossref]

8. Moira Loepfe, Anja Duss, Katerina-Alexandra Zafeiropoulou, Oddny Björgvinsdóttir, Matteo D’Este, David Eglin, Giuseppino Fortunato, Juergen Klasen, Stephen J. Ferguson, Karin Wuertz-Kozak, Olga Krupkova. 2019. Electrospray-Based Microencapsulation of Epigallocatechin 3-Gallate for Local Delivery into the Intervertebral Disc. Pharmaceutics 11:9, 435. [Crossref]

9. Biao Duan, Yan Liu, He Hu, Fu-Guo Shi, Ya-Long Liu, Hao Xue, Xin-Yu Yun, Ming-Yu Yan, Xi-Rui Han, An-Fu Chen, Yong Wang, Zhe-Hai Li. 2019. Notch1-ADAM8 positive feed-back loop regulates the degradation of chondrogenic extracellular matrix and osteoarthritis progression. Cell Communication and Signaling 17:1. . [Crossref] 